\title{
Marine chemical ecology: what's known and what's next?
}

\author{
Mark E. Hay \\ University of North Carolina at Chapel Hill, Institute of Marine Sciences, 3431 Arendell St., Morehead \\ City NC 28557, USA
}

\begin{abstract}
In this review, I summarize recent developments in marine chemical ecology and suggest additional studies that should be especially productive. Direct tests in both the field and laboratory show that secondary metabolites commonly function as defenses against consumers. However, some metabolites also diminish fouling, inhibit competitors or microbial pathogens, and serve as gamete attractants; these alternative functions are less thoroughly investigated. We know little about how consumers perceive secondary metabolites or how ecologically realistic doses of defensive metabolites affect consumer physiology or fitness, as opposed to feeding behavior. Secondary metabolites have direct consequences, but they do not act in isolation from other prey characteristics or from the physical and biological environment in which organisms interact with their natural enemies. This mandates that marine chemical ecology be better integrated into a broader and more complex framework that includes aspects of physiological, population, community, and even ecosystem ecology. Recent advances in this area involve assessing how chemically mediated interactions are affected by physical factors such as flow, desiccation, UV radiation, and nutrient availability, or by biological forces such as the palatability or defenses of neighbors, fouling organisms, or microbial symbionts. Chemical defenses can vary dramatically among geographic regions, habitats, individuals within a local habitat, and within different portions of the same individual. Factors affecting this variance are poorly known, but include physical stresses and induction due to previous attack. Studies are needed to assess which consumers induce prey defenses, how responses vary in environments with differing physical characteristics, and whether the 'induced' responses are a direct response to consumer attack or are a defense against microbial pathogens invading via feeding wounds. Although relatively unstudied, ontogenetic shifts in concentrations and types of defenses occur in marine species, and patterns of larval chemical defenses appear to provide insights into the evolution of complex life cycles and of differing modes of development among marine invertebrates. The chemical ecology of marine microbes is vastly underappreciated even though microbes produce metabolites that can have devastating indirect effects on non-target organisms (e.g., red tide related fish kills) and significantly affect entire ecosystems. The natural functions of these mctabolitcs arc poorly understood, but they appear to deter both consumers and other microbes. Additionally, marine macro-organisms use metabolites from microbial symbionts to deter consumers, subdue prey, and defend their embryos from pathogens. Microbial chemical ecology offers unlimited possibilities for investigators that develop rigorous and more ecologically relevant approaches.
\end{abstract}


Keywords: Benthic invertebrates; Chemical defenses; Marine secondary metabolites; Microbes; Plant-herbivore and predator-prey interactions; Seaweeds

\section{Introduction}

During the last two decades, marine chemical ecology has matured from a science where natural products chemists discovered secondary metabolites and assumed ecological functions, or where biologists observed ecological interactions and assumed the underlying chemical mechanisms, into a stronger field where chemical and biological aspects are simultaneously investigated using ecologically realistic conditions. The exponential growth in reviews focused on aspects of marine chemical ccology is an indication of the dramatic advances being made and of the widespread interest in this field (Bakus et al., 1986; Hay and Fenical, 1988, 1992, 1996; Duffy and Hay, 1990; Hay, 1991a; Hay and Steinberg, 1992; Paul, 1992; Pawlik, 1992, 1993; Fenical, 1993; McClintock, 1994). Because previous reviews are both recent and comprehensive, I will provide a concise, rather than comprehensive, overview of our present knowledge and a discussion of (i) what we still need to know, (ii) what conceptual or methodological limitations hinder future progress, and (iii) what areas provide the greatest opportunity for advancing our understanding of marine chemical ecology.

Because all life processes have chemical underpinnings, chemical ecology can justifiably include a huge variety of topics (much of biochemistry, digestive physiology, biogeochemistry, etc.,) circumscribing much more than can be covered here. In this review, I focus on the ecological function of secondary, as opposed to primary, metabolites and on areas where information is available for both ecological processes and the chemical mechanisms affecting them.

\section{Distribution and diversity of marine secondary metabolites}

Secondary metabolites appear to be most common and most ecologically important among tropical benthic organisms that are subject to high rates of attack by consumers on coral reefs (Hay and Steinberg, 1992; Paul, 1992; Pawlik, 1993; Faulkner, 1994; Bolser and Hay, 1996). However, secondary metabolites also play important roles in temperate (King, 1986; Hay and Steinberg, 1992; Steinberg, 1992; Woodin et al., 1993; Duffy and Hay, 1994; Cronin and Hay, 1996a,b) and Antarctic benthic communities (McClintock, 1994), and possibly in pelagic (Huntley et al., 1986; Paerl, 1988; Shaw et al., 1995b) communities world-wide. Novel secondary metabolites, including terpenes, acetogenins, alkaloids, and polyphenolics, are produced by a wide variety of marine organisms, with some of these compounds differing fundamentally from terrestrial secondary metabolites in that they are halogenated and often possess chemical structures that are unprecedented among terrestrial organisms. To date, several thousand marine secondary metabolites have been described from sponges, ascidians, soft corals, bryozoans, polychaetes, seaweeds, marine microbes, and other benthic and pelagic 
organisms (Fenical, 1993; Faulkner, 1994 and his previous reviews cited therein). As one example of the chemical diversity that can occur in marine organisms, members of the red algal genus Laurencia produce over 500 different terpenes representing at least 26 different structural classes, more than 16 of which are novel and found only in Laurencia (Faulkner, 1994 and previous reviews).

Although the natural function of most marine secondary metabolites remains uninvestigated, many secondary metabolites have been demonstrated to serve as defenses against consumers, competitors, fouling organisms, and pathogens or to play a role in reproduction. There is also abundant evidence for site-specific chemical cues that promote or deter settlement of marine larvae. However, metabolites affecting settlement have rarely been identified, and those that are known are usually not secondary metabolites and have not been demonstrated to cue settlement under natural conditions. Pawlik (1992) provides a thorough review of this topic.

\section{The ecological function of marine secondary metabolites}

\subsection{Defense against consumers}

Marine studies of among-species differences in susceptibility to consumers and presence of secondary metabolites have provided insights into factors (a) driving ecological specialization (Hay, 1992), (b) affecting species' distribution and community organization (Lubchenco and Gaines, 1981; Hay, 1985, 1991a; Estes and Steinberg, 1988; Kvitek et al., 1991), (c) determining feeding patterns and digestive efficiencies (Horn, 1989; Hay, 1991a; Irelan and Horn, 1991; Pennings and Paul, 1992; Targett et al., 1995), and (d) producing parallels and contrasts between marine and terrestrial systems (Hay, 1991b; Hay and Steinberg, 1992). An increased understanding of prey chemical defenses is thus fundamental to a wide range of ecological and evolutionary topics.

Large numbers of investigations have demonstrated in both field and laboratory assays that secondary metabolites from seaweeds and benthic invertebrates serve as defenses against consumers (reviewed by Hay, 1991a; Hay and Steinberg, 1992; Paul, 1992; Pawlik, 1993; Pawlik et al., 1995). Because consumer pressure in marine systems is so high and because these systems are often more experimentally tractable and less disturbed than terrestrial systems, it has been possible to clearly identify ecologically important consumers that compounds should be tested against, or to test compounds in the field against the diverse assemblage of natural consumers that occur there (reviewed by Hay and Steinberg, 1992). Thus, marine investigators can apply purified metabolites at natural concentrations to the surfaces of otherwise palatable organisms or can imbed the metabolites in experimental foods placed on natural reefs, and determine in a very short period of time whether or not the compounds would decrease predation under natural field conditions (Hay, 1991a; Hay and Steinberg, 1992; Pawlik et al., 1995). This ability to assay secondary metabolites under field conditions in remote locations where the densities and diversities of natural enemies have been minimally affected by man is 
relatively unique to marine systems. In this respect marine investigators are advantaged over their terrestrial counterparts; field bioassays of prey chemical defenses have rarely been conducted in undisturbed terrestrial communities.

Prey chemical defenses are especially important on tropical coral reefs where fishes may bite the bottom in excess of 150000 times $/ \mathrm{m}^{2} /$ day, and where either fishes alone or urchins alone are capable of removing almost $100 \%$ of daily productivity (Carpenter, 1986). In areas where these generalist consumers feed so intensively, small mesograzers like amphipods and polychaetes that live on the plants they consume would rapidly be eaten if they lived on plants that were preferred by fishes. It was, therefore, hypothesized that selection should favor sedentary mesograzers that could live on and eat seaweeds that were chemically defended from fishes (Hay et al., 1987; Hay, 1992). The same general hypothesis should hold for nudibranchs, shrimp, crabs, and other small consumers that live in association with benthic invertebrates (see Pawlik, 1993; Cronin et al., 1995 for examples). Initial tests of this hypothesis in the temperate Atlantic found that the tube-building amphipod Ampithoe longimana and the tube-building polychaete Platynereis dumerilii both minimized contact with fishes by selectively living on and consuming the brown alga Dictyota menstrualis, which produced diterpene alcohols that deterred fish feeding but that had little effect on feeding by the amphipod or polychaete (Hay, 1992; Duffy and Hay, 1994). In seasons when fishes were common, amphipod species that could not tolerate algal chemical defenses went locally extinct, while the amphipod Ampithoe longimana remained abundant because it used defended algae as safe sites from fish predation (Duffy and Hay, 1994; and references therein).

The hypothesis that small sedentary consumers could minimize predation by associating with, or specializing on, toxic hosts has been tested more broadly using amphipods, crabs, and mollusks that live on chemically defended seaweeds or benthic invertebrates in the Caribbean or tropical Pacific (reviewed by Hay, 1992; Paul, 1992; Pawlik, 1993). In all of these cases, mesoconsumers were undeterred, or sometimes stimulated, by host compounds that deterred fish feeding. Additionally, predation on the mesoconsumers was reduced through their association with these chemically noxious hosts (Hay, 1992). As an example (Hay et al., 1990), the Caribbean amphipod Pseudamphithoides incurvaria lives in a mobile, bivalved domicile that it constructs from the chemically defended seaweed Dictyota bartayresii. The diterpene alcohol pachydictyol A that causes fishes to reject the alga as food is the compound that cues domicile building by the amphipod. Amphipods in domiciles built from this alga are rejected as food by predatory fishes but are rapidly eaten if they are removed from their domiciles or if they are in domiciles that they have been forced to build from a seaweed that is not chemically defended. Although the amphipod cannot physiologically sequester its host's chemical defenses, it achieves this behaviorally by building its domicile from the alga.

The Spanish dancer nudibranch, Hexabranchus sanguineus, provides a well documented example (reviewed in Pawlik, 1993) of physiological sequestration of host chemical defenses by a mesoconsumer that preys on a benthic invertebrate. The nudibranch feeds on sponges in the genus Halichondria; these sponges contain oxazole macrolides that deter feeding by fishes. The nudibranch alters these compounds slightly and concentrates them in its dorsal mantle and egg masses, where they serve as defenses against consumers. Concentrations of the macrolides are low in the sponge, higher in the 
nudibranch, and highest in the nudibranch egg masses, but even the lowest natural concentrations result in strong suppression of feeding by fish. A taxonomically diverse assemblage of these more specialized mesograzers escape detection or deter their consumers by living on, feeding from, and, in some cases, morphologically mimicking or sequestering defensive compounds from their toxic hosts (see Hay, 1992; Hay and Steinberg, 1992; Paul, 1992; Pawlik, 1993).

A variety of planktonic organisms, including diatoms and dinoflagellates, also produce secondary metabolites; however, the ecological function of these metabolites is not well known. One of the major impediments to advances in this general field is the difficulty of conducting ecologically realistic bioassays on the effects of metabolites produced by microbes like diatoms. As an example, (Shaw et al., 1995a,b) found that the diatoms Phaeodactylum tricornutum and Thalassiosira pseudonana produced apo-fucoxanthinoids that appeared to deter feeding by copepods. Even though these compounds are held in the diatom cells and not released into the water, they tested the activity of these compounds by dissolving them into the water holding the copepods and measuring fecal production as an indication of feeding suppression. A decrease in fecal production was interpreted as a result of feeding deterrence even though the effect could have been caused by physiological stress, a narcotic effect that diminished activity levels, or an effect on gut passage rate instead of feeding. Although these conditions may affect copepod feeding, compounds that produce these effects are not necessarily feeding deterrents - altered temperature or salinity could produce these same effects.

These types of assays were commonly used on micro-organisms 20 years ago (and are still used by some investigators) but they have important limitations for evaluating ecological phenomena. As an example, low dosages of several algal metabolites killed omnivorous fishes in 1-3 min when placed in their water, but no negative effects of these compounds were noted when fish were forced to eat this same dosage of these compound every day for 2-3 weeks (M.E. Hay and L. Matthews, unpubl. data). Numerous investigators have shown that there is no predictive relationship between the effect of a compound placed in an organism's water and the effect of that compound if it is eaten by the organism (Hay and Fenical, 1988; Sammarco and Coll, 1992; Pawlik et al., 1995). Attempts to assess the physiological effects of prey metabolites on consumers by dissolving metabolites into water holding the consumer have minimal ecological relevance and should be discontinued. Such procedures may be no more realistic than suffocating humans in chocolate syrup and then concluding that chocolate is toxic.

The many bioactive compounds produced by marine micro-organisms like diatoms and dinoflagellates have obvious potential as feeding deterrents, but an appropriate food needs to be developed to rigorously test this hypothesis. Tamburri and Zimmer-Faust (1996) recently fed oysters $250 \mu \mathrm{m}$ chromatography beads coated with larval extracts of differing polarities to evaluate the chemical cues that oysters used in food selection. This type of methodological approach offers considerable promise for evaluating questions related to microbial chemical ecology - especially if a food particle equivalent in size and food quality to the prey organism can be substituted for the beads. In general, the chemical ecology of marine micro-organisms is vastly underappreciated and offers considerable opportunity for experimentation and new discoveries (see Huntley et al., 1986; Zimmer-Faust et al., 1996b as examples). 


\subsection{Ecosystem-wide indirect effects}

Although the ecological function of microbial metabolites have rarely been unambiguously determined, the potential indirect effects of these compounds on non-target organisms and on ecosystem function can be considerable. The paralytic shellfish toxins acquired by bivalves as they ingest dinoflagellates may have large-scale cascading effects on community structure through their indirect effects on keystone species such as sea otters or other predators, which can play a large part in structuring nearshore temperate ecosystems (Simenstad et al., 1978; Kvitek et al., 1991). As an example, filter feeding butter clams, Saxidomus giganteus, along the west coast of North America, are immune to the effects of paralytic shellfish toxins. They, therefore, feed on toxic dinoflagellates and concentrate toxins from these prey. Sea otters, fishes, and birds foraging on butter clams are not immune to the toxins and can become sick, or die, if they ingest the compound-laden portions of clams that have fed on toxic dinoflagellates. Kvitek et al. (1991) hypothesized that dinoflagellate toxins affected the regional distribution of sea otters. They noted that otters appear to have been historically absent from areas where dinoflagellate blooms were common, but historically present in areas where dinoflagellate blooms were rare. Because sea otters are such voracious urchin predators, areas with otters have low densities of urchins but abundant kelp beds that attract fishes and pinnipeds; the kelp beds also provide organic matter that contributes to the growth of a broad range of other nearshore species (Simenstad et al., 1978; Duggins et al., 1989). If otters are absent, urchin grazing can destroy kelp beds, create urchin barrens, and dramatically alter ecosystem structure and function. Thus, toxins from planktonic dinoflagellates have the potential to substantially alter the structure and productivity of nearshore ecosystems through their indirect effects on keystone consumers like sea otters (Kvitek et al., 1991).

Even when the effects are not mediated by keystone species like otters, ecosystemwide and chemically-mediated effects of toxic phytoplankton (e.g., red tides) can be dramatic (Paerl, 1988). Blooms of toxic dinoflagellates can result in large scale die-offs of scallops, fishes, and other non-target organisms, and in the loss of millions of dollars in fisheries revenues. Along the Gulf Coast of the United States, outbreaks of the toxic dinoflagellate Ptychodiscus brevis have been estimated to kill up to 100 tons of fish per day, and similar effects of dinoflagellate blooms are known world-wide (Paerl, 1988). Although the frequency of toxic plankton blooms appears to be increasing and to be having large economic consequences, the relative direct and indirect roles of secondary metabolites, increased oxygen demand, or other co-occurring environmental stressors on the system are still inadequately understood.

As additional examples of the potential indirect effects of secondary metabolites, phenolics from seaweeds or other marine plants can affect humic materials, water color, and chelation of ions in near-shore waters, and when chemically defended organisms die, they may be largely unavailable to detritivores until their bioactive metabolites degrade (see discussion in Hay, 1992). Therefore, secondary metabolites may indirectly affect characteristics of nearshore water columns, detrital pathways, and ecosystem-level processes such as carbon flow and nutrient cycling. 


\subsection{Antifouling, antimicrobial, and allelopathic effects}

Some marine secondary metabolites almost certainly function as antifouling, antimicrobial, or allelopathic agents (Bakus et al., 1986; King, 1986; Pawlik, 1992; Woodin et al., 1993; de Nys et al., 1995; Schmitt et al., 1995), but methodological difficulties have limited development of this area of investigation. Many marine secondary metabolites or crude extracts have been shown to inhibit settlement of fouling organisms, but the ecological interpretation of most of these data are difficult because compounds that are contained in organisms are usually extracted and tested on surface exteriors without showing that fouling organisms would ever contact these compounds on natural surfaces and without running adequate controls for the effects of the oily physical characteristics of some of the extracts.

Studies assessing antifouling roles of marine natural products need to demonstrate that potential hosts are unusually resistant to fouling, that compounds which could affect fouling are present on the surface of the potential host, and that these compounds do indeed affect settlers. As an example, Schmitt et al. (1995) noted that plants of the brown alga Dictyota menstrualis were less frequently and less heavily fouled than other co-occurring seaweeds. In lab assays, larvae of the fouling bryozoan Bugula neritina rejected Dictyota as a settling site even though they contacted its surface as often as they contacted the surface of a preferred host alga. Rejection occurred only after direct contact with the alga's surface, and rejection was not mediated by water-borne chemical cues or by surface wettability (a physical property of the surface that can affect fouling). The lipid-soluble extract from surface rubbings of Dictyota contained the diterpene alcohols pachydictyol $\mathrm{A}$ and dictyol $\mathrm{E}$ and inhibited larval settlement when placed on other surfaces. Larvae exposed to these compounds experienced mortality, abnormal development, or reduced rates of development. These observations suggest that this alga deters fouling via the use of secondary metabolites.

Given the intensive competition for space on marine hard substrates (Jackson, 1977), chemically-mediated allelopathic interactions could be common; however, few studies have adequately addressed both the chemical and ecological aspects of marine allelopathy. The more thorough studies (Porter and Targett, 1988; de Nys et al., 1991) use field experimentation to demonstrate both that one species directly inhibits another and that this inhibition occurs via a chemical mechanism. As an example, de Nys et al. (1991) demonstrated that benthic invertebrates in the field experienced tissue necrosis when they contacted the red alga Plocamium hametum. When the lipophilic extract of the alga was transferred onto plastic aquarium plants, these plants caused tissue damage to nearby invertebrates while similar plants without the extract did not. A major methodological problem inhibiting the advancement of studies focused on allelopathy is the difficulty of determining what chemicals are on an organism's surface (where they can affect foulers or nearby competitors) versus embedded in an organism's tissues and not released to the surface. There have been some crude attempts to study surface chemistry (Schmitt et al., 1995) but significant improvements are needed.

Given that microbial pathogens can dramatically reduce marine populations over thousands of kilometers (Lessios, 1988; Littler and Littler, 1995) and that many 
secondary metabolites have broad bioactive effects, these compounds might also serve as defenses against microbial pathogens. Although feasible, ecologically realistic assays of this possibility have not been conducted. Raghukumar and Chandramohan (1988) found that a green alga doubled its production of phenolics in response to fungal infection, suggesting that phenolics might function as antibiotics - as they often do in terrestrial systems (Schultz et al., 1992). Expanded, but more ecologically realistic, studies of antifouling, antimicrobial, and allelopathic interactions are needed - especially given the potential applied applications of such investigations (de Nys et al., 1995).

\section{Feeding stimulants and prey attractants}

Most chemical ecology research has focused on defenses against predators (Hay and Steinberg, 1992; Paul, 1992; Pawlik, 1993). Feeding stimulants and compounds that consumers use to search for food are of equal importance but are less thoroughly studied within an ecological context. Sakata (1989) reviews feeding attractants and stimulants for marine gastropods. These studies show that specific amino acids, sugars, carbohydrates, glycerolipids, etc., can attract or repel gastropods. Most of this work has used commercially available compounds rather than bioassay-guided discovery of the metabolites that affect feeding in nature. Tamburri and Zimmer-Faust (1996) found that oysters consumed numerous species of invertebrate larvae and that their recognition and acceptance of a food particle was determined by polar and nonpolar organic metabolites on the larvae's surface, rather than by water soluble metabolites. Zimmer-Faust and co-investigators have also conducted extensive investigations of how crabs use odor plumes to detect bivalve prey in the field (Weissburg and Zimmer-Faust, 1993, 1994; Zimmer-Faust et al., 1995, 1996a). Although the exact chemical nature of the prey odors attracting the crabs has not been determined, these investigators do an exceptional job of running their assays in ecologically realistic flow regimes and determining how flow conditions will interact with predator chemosensory ability and behavior to determine foraging success and the role that odors may play in this. This integration of chemical signaling into more realistic physical conditions (rather than the more standard Y-tube assays) is a valuable and needed advancement.

\section{Spatial and temporal patterns in the distribution of secondary metabolites}

\subsection{Geographic patterns}

Understanding the distribution and abundance of prey chemical defenses at various spatial and temporal scales is illustrative of both the evolutionary processes that may be shaping prey defenses and of the ecological consequences of these defenses. The distribution of secondary metabolites over temporal, geographic, between-individual, and within-individual scales all suggests that these compounds often serve as defenses against consumers.

Both tropical plants and benthic invertebrates have been hypothesized to need stronger 
defenses against consumers due to the perceived increase in consumer activity at lower latitudes (see discussion in Bolser and Hay, 1996). Supporting evidence for greater consumer pressure in the tropics comes from a wide range of terrestrial and marine systems, and includes temperate-tropical comparisons of the secondary metabolites of sponges and sea cucumbers (Bakus and Green, 1974), protective shell architecture of gastropods (Vermeij, 1987), predation by marine fishes on gastropods (Bertness et al., 1981), sessile benthic invertebrates (Menge and Lubchenco, 1981), and decapod crustaceans (Heck and Wilson, 1987), and insect damage of, and levels of phenolics in, forest trees (Coley and Aide, 1990). These diverse studies suggest that because the intensity of herbivory and predation is greater, the levels of prey defense should be higher in tropical than in temperate habitats.

Very little direct, experimental evidence exists, however, to support the hypothesis that temperate prey are really more susceptible to consumers, or that tropical prey have more strongly developed defenses. Numerous findings suggest the need to more rigorously investigate the hypothesized latitudinal trend in prey defenses, or susceptibility to consumers. For example, although antiherbivore defense is often seen as the 'raison d'etre' of plant secondary metabolites (Herms and Mattson, 1992), not all seaweed secondary metabolites act as feeding deterrents, the deterrent effects of compounds are not always consistent against different herbivores, and secondary metabolites can have functions other than defense against herbivores (Hay and Steinberg, 1992; Paul, 1992; Steinberg and van Altena, 1992; Schmitt et al., 1995). Thus, latitudinal patterns in the occurrence of secondary metabolites need not be related to patterns in anticonsumer defense alone.

Until very recently, no studies had determined that tropical prey were actually less palatable than their temperate relatives, or that the apparent geographic variation in prey secondary metabolites actually affected susceptibility to consumers. A recent study by Bolser and Hay (1996) documented a general pattern in which tropical algae from the Bahamas were less palatable to both a temperate and a tropical urchin than closely related temperate algae from North Carolina, even though all plants had been dried, finely ground, and processed into artificial foods that were morphologically identical. Their results point to lipophilic chemical defenses as a major mechanism generating as much as $60 \%$ of the differences in palatability between North Carolina and Bahamian seaweeds. Water-soluble extracts, protein content, or ash content of the food explained few, if any, of the herbivore feeding choices in their assays.

Other geographic patterns in seaweed secondary metabolites have also been reported. Contrasts within the Pacific indicated that temperate brown algae produced much higher levels of phlorotannins than tropical brown algae - in contrast to the general pattern expected for temperate versus tropical algae (Steinberg, 1989, 1992; Van Alstyne and Paul, 1990). This pattern was initially hypothesized to result from phlorotannins being ineffective defenses against tropical herbivorous fishes, but direct tests by Van Alstyne and Paul (1990) found that reef fishes in the tropical Pacific were deterred from feeding by the phenolic-rich extracts from temperate brown algae but not by the phenolic-poor extracts from tropical brown algae. However, susceptibility of the temperate versus tropical plants (as opposed to extracts) was not tested. The possibility that nonpolar chemical defenses were stronger in tropical than in temperate algae or that the algae 
differed in nutritive value was not evaluated. Additionally, recent work in the Caribbean has shown that tropical brown seaweeds can be rich in phlorotannins (Targett et al., 1992) but that this appears to have no effect on the digestive efficiency of several common herbivores (Targett et al., 1995). Thus, there is little evidence that phlorotannins consistently function as defenses against tropical herbivores (or even temperate ones-Steinberg and van Altena, 1992), and expectations for the role of phlorotannins in defending temperate versus tropical algae are unclear.

Because large polar compounds like phlorotannins are difficult to separate, purify, and chemically identify, biologists have almost invariably worked with chemically uncharacterized phenolic mixtures that they measured crudely as 'total phenolics' using a simple colorimetric assay that has several limitations (Watterman and Mole, 1994). Boettcher and Targett (1993) demonstrated that some sized phlorotannins negatively affected herbivores while others did not, clearly indicating the need to determine which phlorotannins occur in a prey, and not just the total concentration of all different phlorotannins. The high concentrations and broad geographic distributions of phlorotannins suggest that they may be of considerable ecological importance. This area is in need of more rigorous qualitative and quantitative chemistry. Investigations that build on the approach used by Boettcher and Targett (1993) should be favored over those measuring total phenolics.

Comparisons of algal phlorotannin concentrations between temperate regions that differ in their paleohistories of sea urchin grazing suggest that phlorotannins are more abundant in areas impacted by urchins (Estes and Steinberg, 1988; Steinberg and van Altena, 1992; Steinberg et al., 1995). Sea otters along the Pacific coast of North America are voracious urchin predators and are proposed to have historically limited urchin numbers in this region. This resulted in low densities of urchins, large densities of kelps, and limited selection for kelps to evolve chemical defenses, or for urchins to evolve a tolerance for these defenses. In contrast, the absence of an ecologically similar urchin predator in temperate Australasia is proposed to have resulted in large numbers of urchins, heavy grazing on kelps, and thus stronger selection for kelps to evolve chemical defenses and for urchins to become tolerant to these. Present-day contrasts between these two biogeographic regions (Steinberg et al., 1995) show: (1) that herbivory is significantly higher at Australasian sites than at North American sites that have otter populations, (2) that common Australasian brown algae have phlorotannin concentrations that are almost three times greater than concentrations for common North American species, and (3) that feeding by Australasian urchins and gastropods is generally unaffected by natural concentrations of phlorotannins from either region, while feeding by North American urchins and gastropods is generally deterred by natural concentrations of phlorotannins from both regions. These data support the original hypothesis of Estes and Steinberg (1988) regarding the importance of paleograzing patterns in generating geographic patterns of algal secondary metabolites. It is disquieting, however, that Australasian algae continue to produce phlorotannins at such high concentrations when they have no defensive value against local herbivores. This suggests that even high levels of phlorotannins (up to $16 \%$ of algal dry mass) don't involve significant costs to the alga, or that these compounds are playing other important roles that are not recognized and that also differ between these geographic regions. 
Many investigators have offered their perceptions about how concentrations or diversities of marine secondary metabolites vary with latitude. Few investigations have provided data facilitating a rigorous assessment of these general perceptions (Steinberg and van Altena, 1992; Targett et al., 1992, 1995; Bolser and Hay, 1996). Broad assessments of palatabilities or chemical deterrencies to consumers are available for Caribbean sponges (Pawlik et al., 1995), gorgonians (Pawlik et al., 1987), seaweeds (Hay, 1984; Paul and Hay, 1986), and the larvae from several groups of Caribbean invertebrates (Lindquist and Hay, 1996). Comparative studies from other biogeographic provinces would be useful.

\subsection{Intraspecific patterns}

Understanding within-species variance in defensive mechanisms and its effects on consumer-prey interactions is critical because this variance: (a) is the variance upon which evolution acts, (b) is largely undocumented, and thus underappreciated, in marine systems, (c) has important implications for population regulation, the development of pharmaceutical and agrochemical products from the sea (Hay and Fenical, 1996), and (d) for understanding the genetic vs. phenotypic component of marine biodiversity. Studies of intraspecific variability in plant defense have been crucial in the development of effective plant breeding programs for both agriculture and ecosystem management (Karban, 1992; Fritz and Simms, 1992; Alstad and Andow, 1995). The proven importance of these terrestrial studies (see the hundreds of papers cited in Denno and McClure, 1983; Tallamy and Raupp, 1991; Fritz and Simms, 1992) suggests that similar studies on marine organisms might be especially valuable.

There is considerable information on among-species differences in palatability, the specific chemical defenses producing these differences, and potential effects on ecological and evolutionary patterns and processes (see Hay, 1991a; Hay and Steinberg, 1992; Paul, 1992; Pawlik et al., 1995; Hay and Fenical, 1996). There is very little information on intraspecific variance in palatability, the causes of this, and the repercussions for population and community organization. Although intraspecific variance in metabolite production is just beginning to be investigated, variance among different parts of one organism, among different individuals in a population, and among different populations of the same species appears to be considerable for some species (Hay and Steinberg, 1992; Harvell et al., 1993; Cronin and Hay, 1996a,b,c,d; Bolser and Hay, 1996). Whether this variance is genetic or environmentally controlled is not adequately known, but, given the ecological effects of marine secondary metabolites (Paul, 1992), this variance could have significant ecological effects.

As one example with applied consequences, the bryozoan Bugula neritina contains a group of compounds called bryostatins, some of which strongly inhibit human cancer cells. The most important drug from this group is bryostatin 1, which is in human clinical trials as an anticancer drug. Bryostatin 1 is found in Bugula from only a few of the several sites that have been investigated (Pettit, 1991). Thus, if conservation efforts aimed at the preservation of marine biodiversity had succeeded in protecting this species, but not these specific populations, then Bugula's potential contribution to cancer therapy would have been lost. For marine organisms in general, the frequency and magnitude of 
intraspecific variation in secondary metabolites is not known, but variation appears common.

Harvell et al. (1993) found that the gorgonian Briarium asbestinum was defended from consumers by a complex mixture of 5-15 different secondary metabolites, but that there was often dranlatic variation in qualitative and quantitative aspects of these metabolites between depths at a site, between sites within a region, and between geographic areas. Shallow colonies transplanted to greater depths for 7 months increased their concentrations of secondary metabolites but did not change qualitatively, suggesting that there was environmental control of compound concentration, but that the type of compounds being produced was genetically fixed. The ecological consequences of these patterns and the environmental cues producing them remain uninvestigated.

As a final example, when Bolser and Hay (1996) compared the palatability and chemical defenses of a large number of related temperate and tropical seaweeds, they found that tropical seaweeds tended to be significantly less palatable and better defended. However, contrasts within the brown algal genus Dictyota showed dramatic within-species variance that was equivalent to the total variance seen among species across different geographic regions. A population of Dictyota menstrualis from a shallow site in North Carolina was significantly more palatable than 4 of 6 tropical species of Dictyota, while a population of this same species from a deeper site in the same region was significantly less palatable than 4 of the 6 tropical species. Chemical extracts from the more palatable population were less deterrent than extracts from most of the tropical species, while extracts from the less palatable population were more deterrent than extracts from most of the tropical species.

Although limited in number, studies on intra-individual variation in chemical defenses have also provided ecologically important insights into allocation of defenses and the consequences for both consumers and prey. As examples, secondary metabolites in seaweeds are often concentrated in the outer meristoderm layers of the thallus (Tugwell and Branch, 1989), in the actively growing meristematic regions (Hay et al., 1988; Paul and Van Alstyne, 1988; Tugwell and Branch, 1989; Poore, 1994), in the upright vs. the basal portions (Meyer and Paul, 1992), and often, but not always (Tuomi et al., 1989), in the reproductive blades (Steinberg, 1984; Tugwell and Branch, 1989). Gorgonians, soft corals, and bryozoans often show similar patterns, with chemical defenses being most concentrated in the softer, terminal, and less structurally defended areas of colonies (Harvell and Fenical, 1989; Van Alstyne et al., 1992).

\section{Factors influencing intraspecific variance in secondary metabolites}

\subsection{Induction due to attack}

The production of chemical defenses is believed to be costly because defenses utilize resources that could have been allocated to growth or reproduction (Herms and Mattson, 1992). Constitutive defenses require expenditure of resources even when consumers are absent and the benefits of protection are not realized. In contrast, inducible defenses allow costs to be deferred until enemies have been detected, at which time the costs can 
be offset by the benefits of protection. Induced resistance may therefore minimize costs by keeping defenses low until they are needed (Harvell, 1990; Baldwin, 1994).

For some seaweeds, the pattern of variation in secondary metabolites suggests that herbivore-induced increases of chemical defenses may be responsible for some intraspecific variation in concentrations of secondary metabolites. For example, seaweeds from areas of coral reefs where herbivory is intense often produce more potent and higher concentrations of chemical defenses than plants from habitats where herbivory is less intense (Paul and Fenical, 1986; Paul and Van Alstyne, 1988). However, in the green seaweeds Halimeda, Udotea, and Caulerpa that show this pattern, clipping experiments failed to induce increased terpenoid chemical defenses (Paul and Van Alstyne, 1992). Clipping or urchin grazing of temperate seaweeds also failed to induce higher levels of phlorotannins in the kelps Ecklonia and Alaria or in the rockweed Sargassurn (Pfister, 1992; Steinberg, 1994, 1995). Thus, the higher levels of constitutive chemical defenses from sites with many herbivores could have been generated by preferential grazing that removed the more susceptible individuals, founder effects, local selection, or among-habitat differences in other variables.

Additionally, for some of the siphonous green seaweeds studied by Paul and Van Alstyne (1992), weakly deterrent metabolites stored in the alga were immediately converted to more strongly deterrent metabolites if the alga was damaged by crushing or cutting it. To distinguish this rapid enzymatic conversion of available metabolites from the classic notion of induction, Paul and Van Alstyne termed this process "activation."

There are only two well documented examples of consumers inducing increased production of chemical defenses in marine organisms (Van Alstyne, 1988; Cronin and Hay, 1996c). In contrast, there are many examples of inducible chemical defenses in the terrestrial literature (Baldwin, 1994 and references therein). This discrepancy between marine and terrestrial systems could be due to the different construction of vascular terrestrial plants vs. non-vascular seaweeds (e.g., the induction stimulus from localized damage may not be efficiently translocated in seaweeds- see Cronin and Hay, 1996a); but less research on seaweeds relative to terrestrial plants may also explain the disparity.

Although induction has received considerable attention in terrestrial systems, the occurrence, importance, and consequences of induction are still debated and somewhat unclear (Baldwin, 1990; Tallamy and Raupp, 1991; Alder and Karban, 1994). Most terrestrial investigations of induction have focused on insect grazing, while most marine investigations have focused on larger herbivores such as fishes and urchins rather than on mesograzers, such as amphipods, that may be more ecologically similar to insects (Hay et al., 1987). Mesograzers have been considered to be less important than larger herbivores because of the perception that they remove little seaweed biomass relative to the larger herbivores (see the debate among Bell, 1991; Duffy and Hay, 1991b; Brawley, 1992).

Ignoring mesograzers as potential inducers of seaweed chemical defenses is probably inappropriate. The two clear examples of induction in seaweeds (Van Alstyne, 1988; Cronin and Hay, 1996c) both involve mesograzers (a snail and an amphipod), each of which could graze for long periods on a plant without killing it and could thus be affected by a defense that took days, or weeks, to induce. In contrast, fishes and urchins are large relative to many seaweeds and are often capable of rapidly killing a plant that 
they find palatable. Thus, to avoid being killed by these larger more mobile herbivores, plants may need to be constantly defended rather than inducing defenses following attack. For many chemically defended seaweeds and invertebrates, low concentrations of chemical defenses are generally effective deterrents against fishes and urchins, but are less effective or may even stimulate feeding by mesograzers (Hay et al., 1987; Hay, 1991b, 1992; Van Alstyne and Paul, 1992; Pawlik, 1993; Duffy and Hay, 1994). Thus, constitutive levels of chemical defenses appear to be effective against the larger consumers.

I hypothesize that it is feeding by the smaller, less mobile mesograzers that will cue induction of chemical defenses in benthic prey. These types of consumers feed over temporal and spatial scales that would allow induced responses to be beneficial to the prey, and it is the mesograzers that often are not deterred by chemical defenses until the metabolites are induced to higher levels (Cronin and Hay, 1996c; Deal and Hay, unpublished data 1996). It is therefore possible that induction in seaweeds has appeared uncommon, because it rarely occurs in response to clipping or grazing by larger herbivores, but occurs more often in response to mesograzer feeding.

There are too few studies of chemical induction in marine prey to adequately evaluate the relative importance of large mobile versus small sedentary consumers in inducing chemical defenses. However, the results of Cronin and Hay (1996c) illustrate that mesograzer feeding can cause induction of increased chemical defenses in seaweeds. These authors found that the brown alga Dictyota menstrualis from mud-flat habitats was less palatable to the amphipod Ampithoe longimana than D. menstrualis from a nearby jetty. In mud-flat sites where amphipod-eating fishes were less common, amphipods were abundant, their grazing on Dictyota was appreciable, and the alga contained high levels of defensive diterpene alcohols. In hard-substrate sites where fishes were abundant, amphipods were rare, did little damage to Dictyota, and the alga contained significantly lower levels of the defensive diterpenes. When given a choice in the lab, amphipods preferred to graze plants from the jetty site where plants had lower levels of secondary metabolites. When these plants were split and grown in the field for 2-3 weeks with one half of each plant periodically subjected to amphipod grazing and the other half not grazed, plant halves attacked by amphipods produced higher levels of defensive compounds and became less susceptible to amphipod grazing. This lowered susceptibility to amphipods resulted from induction of increased levels of defensive compounds in attacked plants rather than from alterations in plant nutritional content or from previous grazers selectively removing the least defended tissues and thus leaving more chemically-rich tissues. The among-site patterns in palatability and chemical defenses mentioned above occurred in years when amphipods were abundant on mud flats but not in years when they were rare. Thus, both spatial and temporal variance in palatability may have been generated by induced chemical defenses following attack by amphipods.

Additional preliminary experiments (M. Deal and M.E. Hay, in progress) suggest that induction in response to mesograzers also occurs in other seaweeds. When Sargassum plants were transplanted into out-door mesocosms with- and without-mesograzers, plants in mesograzer treatments were damaged severely by amphipod feeding but recovered, while those in treatments without mesograzers always grew well. After several weeks of growing in these two treatments, feeding preference assays demonstrated that amphipods 
preferred plants from the treatments without mesograzers. When plants were dried, finely powdered, and reconstituted in agar (see Hay et al., 1994 for methods), this feeding preference was even more pronounced, suggesting that the feeding differences were generated by chemistry rather than differences in structure or toughness. Neither protein nor phenolic content could explain these feeding patterns, but bioassay-guided chemical investigations indicated that the feeding difference was generated by the butanol-soluble portion of the water-soluble extract. These limited initial findings suggest that Sargassum plants exposed to mesograzers induced a butanol-soluble chemical defense. These findings, along with those of Van Alstyne (1988) and Cronin and Hay (1996c), show that seaweeds are not limited to being passive participants in plant-herbivore interactions, but can actively alter their susceptibility to herbivores in ecological time.

Most investigators that used artificial clipping or larger herbivores like fishes and urchins to look for induction in marine plants failed to find evidence of induction (Paul, 1992; Pfister, 1992; Steinberg, 1994, 1995). However, Van Alstyne (1988) showed that clipping caused increases in Fucus phenolics and that these increases corresponded with decreases in gastropod feeding. Additionally, Yates and Peckol (1993) used Fucus to show that clipping increased phenolics at some times and some sites, but not at others, and Renaud et al. (1990) found that urchin grazing or artificial clipping damage could diminish Padina palatability to urchin grazing; however, they were unable to rigorously show that this was due to induction of a specific chemical defense. In many of the previous marine and terrestrial studies, assays for induction involved measuring changes in chemistry, rather than plant palatability, and even in the more thorough studies that followed changes in herbivore preference (Van Alstyne, 1988; Renaud et al., 1990), it was rare for the compounds (or even crude chemical extracts) thought to be responsible for the change (e.g., phenolics) to be extracted, and directly tested against the herbivore (but see Renaud et al., 1990).

Focusing on chemistry rather than palatability can lead to reasonable, but inaccurate, conclusions. As an example, we used the brown alga Fucus vesiculosus to see if amphipod grazing induced increased resistance to grazers (Deal and Hay, unpublished data 1996). Grazed plant halves increased their phenolic levels by a statistically significant $100 \%$; but, this had no effect on feeding by the amphipods and did not lead to amphipods choosing ungrazed over grazed plants. Increases of specific chemicals following grazing may occur to minimize microbial invasion of wounds, or for other reasons unrelated to the initial grazer. Some terrestrial studies show that microbes entering plants via insect bites have a much greater effect on chemical induction than does the direct damage done by the insect (Raffa and Smalley, 1995); the above example of Fucus could be for similar reasons. Because resistance to consumers can change for reasons other than secondary metabolites, and because concentrations of secondary metabolites can change in response to many factors other than herbivory, studies of induction should assess induction using herbivore feeding, rather than chemical analyses. If feeding is significantly affected, bioassay-guided investigations can then be conducted to directly determine the mechanisms altering resistance. Multifactorial studies to examine the direct, indirect, and interactive effects of how different consumers, types of damage, and aspects of the physical environment affect induced resistance to consumers would be especially valuable.

Additionally, it would be useful to know if chemical defenses are induced by 
competitors, fouling organisms, microbial pathogens, or other natural enemies? If so, would induction caused by microbes, foulers, or consumers, have cascading or reciprocal effects on the other organisms that interact with the prey (e.g., are prey that induce increased defenses in response to consumers therefore subject to less competition from fouling organisms or less attack by microbial pathogens)? If so, was the induction to diminish further consumption or to fight pathogens entering the plant through wounds (see Schmitt et al., 1995 for an example of marine secondary metabolites serving multiple ecological functions)?

\subsection{Physical stresses and prey chemical defenses}

Although induction of chemical defenses in response to herbivore attack helps explain intraspecific differences in palatability for some seaweeds, physical aspects of the environment can also be important. For marine plants, desiccation, UV and visible light, nutrients, and interactions of some of the above factors have been shown to alter seaweed susceptibility to herbivores by compromising chemical defenses or by altering nutritional characteristics that may serve as feeding cues (Renaud et al., 1990; Yates and Peckol, 1993; van Donk and Hessen, 1993; Cronin and Hay, 1996d). Although these alterations are known to occur among both seaweeds and phytoplankton, their effects on palatability under field conditions are relatively unstudied, and without careful experimentation, some of these physically generated changes in palatability can be misinterpreted as induction due to herbivory. As an example, studies of Fucus vesiculosus from the high vs. low intertidal (Deal and Hay, unpublished data 1996) showed low intertidal plants to support higher densities of a Fucus-eating amphipod, to have higher densities of amphipod grazing scars, and to be a lower preference food for these amphipods. These patterns all suggest that amphipod feeding may have induced seaweed defenses in the lower intertidal where amphipods were most active. However, multi-factorial field experiments manipulating amphipod grazing, desiccation during low tide, and exposure to UV radiation, showed that there was minimal induction of resistance due to amphipod grazing, but a large change in palatability due to synergistic effects of low tide exposure and exposure to UV. Reduced preference for lower intertidal plants could be traced to effects of the water-soluble extract. In this example, the correlation of amphipod grazing and increased plant resistance to amphipods was serendipitous rather than causal and resulted from the effects of physical stresses on chemical defenses rather than from induction of defenses due to attack by consumers.

Additionally, Cronin and Hay (1996b) demonstrated that mild desiccation of the brown alga Dictyota ciliolata reduced concentrations of its different secondary metabolites by $7-38 \%$, causing plants to become 2.6-3.4 times more susceptible to urchin and amphipod grazing. The concentrations of secondary metabolites found in undesiccated Dictyota deterred feeding, but this deterrent effect was lost at concentrations found in the desiccated plants. Desiccated and undesiccated plants did not differ in nutritive value or toughness, thus eliminating these traits as confounding factors. Renaud et al. (1990) found a similar pattern for the brown alga Padina gymnospora. They demonstrated that Padina's increased palatability following desiccation resulted from diminished chemical defenses, but they were unable to identify the specific metabolite causing this change. 
Additional studies are needed to determine: (1) which types of consumers and which types of damage result in alterations of prey chemical defenses, (2) how these responses vary in environments with differing physical characteristics, (3) whether the 'induced' responses are a direct response to the consumer or are a defense against microbial pathogens that may be entering through feeding wounds, and (4) the potential effects of these induced defenses on consumer fitness.

\section{Integrated pest management}

Integrated pest management refers to the agricultural practice of limiting crop damage by simultaneously using multiple methods of pest control (natural enemies, pesticides, crop rotation, etc.,) in a coordinated manner. Although secondary metabolites can have strong direct effects on consumer feeding preferences, they do not act in isolation from other plant traits or from the environmental context in which consumer-prey interactions occur. Marine prey also use integrated pest management, and an adequate understanding of chemical defenses will not be achieved until we more fully appreciate the full range of defenses that prey species can use, and how these defenses are integrated. Because most studies of marine chemical defenses have manipulated individual compounds rather than multiple prey traits, much more investigation is needed.

The few studies that are available indicate that prey nutritional quality and prey chemical defenses work in concert to affect prey susceptibility to consumers. When Duffy and Paul (1992) evaluated how marine secondary metabolites affected feeding by reef fishes using foods that differed in their ratios of protein to carbohydrate, they found that some compounds were effective at defending low protein foods but ineffective at defending higher protein foods. Hay et al. (1994) noted a similar pattern when they varied algal concentrations in agar-based foods being consumed by a sea urchin.

The defensive value of secondary metabolites in foods of variable nutritional quality should change as a function of the specific physiological effect of the metabolite on consumers. If compounds lower growth rates or digestive efficiencies rather than survivorship or fecundity, then a consumer might choose a defended high quality food over an undefended lower quality food because the consumer's net income from the defended, but nutritionally rich, prey could be higher. Alternately, if a compound is toxic and strongly affects survivorship or reproduction, then consumers may be selected to avoid such a compound regardless of the nutritional value of the prey.

Chemically defended organisms often produce multiple secondary metabolites, several of which act as feeding deterrents. This provides the possibility for synergistic or additive effects among the multiple metabolites. Investigations are needed on the interactive effects of multiple metabolites; however, the very few studies available at present have rarely found synergistic interactions among secondary metabolites. As an example, when Lumbang and Paul (1996) tested multiple brominated sesquiterpenes produced by the green alga Neomeris annulata against two reef fishes and an urchin, they found that each compound was significantly deterrent at or below its natural concentration and that all of the compounds together were not more deterrent than each 
alone. More studies like this will be needed before the frequency of synergisms can be assessed.

Several studies have indicated that the chemical and structural defenses (i.e., $\mathrm{CaCO}_{3}$ ) that commonly co-occur in both marine plants and benthic invertebrates can function either additively or synergistically to reduce susceptibility to consumers (Hay et al., 1994; Schupp and Paul, 1994; Meyer and Paul, 1995). In one of the more elaborate examples, the calcified alga Halimeda goreauii contains both an unusual secondary metabolite and a heavily calcified thallus. When the effects of the metabolite and the $\mathrm{CaCO}_{3}$ on urchin grazing were tested separately using a nutritionally valuable food, neither had any deterrent effect; however, when these traits were combined they interacted synergistically to strongly deter feeding (Hay et al., 1994). When this assay was repeated using a test food of lower quality, this relationship changed, indicating that food value, $\mathrm{CaCO}_{3}$, and secondary metabolites are all interacting to affect herbivore food choices.

Several species of Halimeda also appear to trade chemical for structural defenses as plant segments undergo development and change their nutritional value and attractiveness to herbivores. Halimeda plants produce new segments that are non-calcified and more nutritious than the rest of the plant. The alga produces these new segments at night while herbivorous fishes are inactive and defends the young segments with more potent and higher concentrations of feeding deterrents than are present in older segments (Hay et al., 1988; Paul and Van Alstyne, 1988). As the new segments calcify, become more heavily invested with structural defenses, and less valuable nutritionally, the concentrations of chemical defenses decrease. Marine chemical ecologists have recently focused more attention on trying to understand prey chemical defenses within broader, more ecologically realistic, and more holistic contexts; these efforts are well founded and need to continue.

Although seaweeds and marine invertebrates commonly use both calcification and secondary metabolites as defenses against consumers, manipulative investigations of defensive characteristics usually study these traits in isolation. This prevents the detection of synergistic effects or the rigorous determination of the relative importance of each type of defense. Organisms such as seaweeds, sponges, ascidians, and soft corals commonly contain both secondary metabolites and possible structural defenses in the form of calcium carbonate $\left(\mathrm{CaCO}_{3}\right)$ granules, spicules, or sclerites. Extensive field and laboratory assays have shown that secondary metabolites from these organisms can function as strong feeding deterrents (Hay, 1991a; Hay and Steinberg, 1992; Paul, 1992; Lindquist et al., 1992; Pawlik et al., 1995). Manipulative experiments on the deterrent qualities of spicules in invertebrates or calcified thalli in seaweeds are less extensive and more variable. Spicules from gorgonians (Gerhart et al., 1988; Harvell et al., 1988; Van Alstyne and Paul, 1992) and soft corals (Van Alstyne et al., 1992) significantly deter fish feeding, while spicules from an ascidian (Lindquist et al., 1992) and numerous species of sponges (Chanas and Pawlik, 1995) do not. Combining these separate assays to determine how chemical and structural defenses might combine to affect prey susceptibilities would be informative, and would more closely mimic the characteristics of real prey.

Calcification of seaweeds and invertebrates has generally been viewed as deterring 
consumers by making prey harder and more difficult to bite or by diminishing their nutritional value due to the addition of indigestible structuring materials (see discussion in Hay et al., 1994). The methods of adding calcite to the artificial foods used in the above experiments did not increase food toughness and did not change the nutritional value of the foods (i.e., nutritional value per bite was held constant); however, calcite alone significantly reduced feeding in several assays with amphipods, sea urchins, a sea hare, and numerous species of herbivorous fishes (Pennings and Paul, 1992; Hay et al., 1994; Schupp and Paul, 1994). These findings do not diminish the potential importance of calcification in increasing prey toughness and thus diminishing consumption, but they do show that calcification can also affect feeding via some other, possibly chemical, mechanism.

One potential mechanism by which $\mathrm{CaCO}_{3}$ might interfere with feeding is the buffering effect that calcium carbonate would have on the gut $\mathrm{pH}$ of consumers that rely on acid-mediated digestion. Ingested calcite might: (1) directly inhibit digestion by neutralizing acid in the guts of consumers, (2) indirectly affect digestion by altering the effectiveness of digestive enzymes, many of which function well only within a narrow range of $\mathrm{pH}$, or (3) increase the effects of co-occurring secondary metabolites if their activity is pH-sensitive as appears to be the case with polyphenolics (Feeny, 1970). Given calcium carbonate's ability to buffer acids, $\mathrm{CaCO}_{3}$ might be expected to have its largest effects on consumers with acidic guts. This hypothesis is consistent with the observation that parrotfishes, which have alkaline guts (Horn, 1989), were not deterred by the addition of calcite, but that surgeonfishes and damselfishes that do have low $\mathrm{pH}$ guts were deterred by calcium carbonate (Schupp and Paul, 1994; Pennings et al., 1996). Our understanding of digestive physiology and biochemistry in marine consumers is so incomplete that no one can confidently suggest reasons for why we find synergisms between secondary metabolites and $\mathrm{CaCO}_{3}$ in assays with some herbivores and compounds but not in others. Even for the best studied groups, like herbivorous fishes (see Horn, 1989), mechanisms of digestion are just beginning to be investigated. Investigations of how specific digestive mechanisms are affected by different suites of defensive characteristics, are just beginning, but should yield important insights.

\section{Associational resistance and shared doom}

A species' susceptibility to consumers is not determined by its deterrent characteristics or food quality per se, but by these properties relative to the characteristics of other members of the community. Since the 1970 s for terrestrial environments and the $1980 \mathrm{~s}$ for marine environments, co-occurring organisms have been shown to strongly influence a prey species' risk of attack (Atsatt and O'Dowd, 1976; Hay, 1986; Littler et al., 1986; Pfister and Hay, 1988). Thus, a preferred species may be less at risk when surrounded by more preferred species than when growing alone, or it may gain protection by growing close to a repellent, or unpalatable, species. In the first case, consumers are detracted from the prey under consideration due to its more attractive neighbors; in the second case, the prey is not discovered because its cues are diluted or masked by those of its repellent neighbors (Atsatt and O'Dowd, 1976). 
Palatable seaweeds that are usually driven to local extinction by grazers can persist in herbivore-rich communities if they grow on or beneath their herbivore resistant competitors (reviewed by Hay, 1992). Numerous species of palatable seaweeds are significantly more common near the base of the chemically defended seaweed Stypopodiurn zonale than several centimeters away; if the deterrent plant is removed, these more palatable species are rapidly eaten (Littler et al., 1986). When plastic mimics of Stypopodium are placed in the field, they also provide a partial refuge for palatable species, but they are less effective than the real plants, suggesting that associational refuges are generated in part by the physical presence of a non-food plant, but that the plant's chemical repugnance makes the associational refuge more effective.

Although planktonic systems are less amenable to field experimentation, similar associational refuges occur there as well. The sluggish pelagic pteropod Clione antarctica blooms each summer in Antarctica, but is not consumed by co-occurring fishes because it produces a potent feeding deterrent (Bryan et al., 1995). In a novel use of associational defense, the palatable amphipod Hyperiella dilatata grasps the noxious pteropod from the water column, holds it on its dorsal surface, and thus becomes equally unpalatable to predatory fishes (McClintock and Janssen, 1990). As a second example, palatable phytoplankton are grazed less heavily, or not at all, when they are mixed among chemically defended dinoflagellates (Huntley et al., 1986).

In temperate communities, palatable seaweeds can minimize losses to herbivorous fishes and urchins by growing near unpalatable seaweeds such as Sargassum filipendula (Hay, 1986; Pfister and Hay, 1988). Growing in close association with these unpalatable competitors depresses the growth of palatable species by as much as $85 \%$, but the associational benefits, in terms of reduced herbivory, can more than offset this competitive cost. Thus, palatable species can be dependent on their unpalatable competitors to prevent their exclusion from the community due to herbivory (Hay, 1986).

Although fouling organisms are generally considered to be detrimental to hosts, they can have positive overall effects if they provide increased resistance to consumers. Feifarek (1987) described how an epibiotic sponge impeded starfish predation on a spiny oyster, Barkai and McQuaid (1988) found that whelks in shells overgrown by a noxious bryozoan were resistant to lobster predation, and Wahl and Hay (1995) found that host seaweeds overgrown by less palatable epiphytes became less susceptible to urchin grazing.

Associational refuges were initially interpreted as arising from simple visual crypsis (Hay, 1986), but more detailed investigations suggest that chemistry may play a significant role in some of these associational escapes (Pfister and Hay, 1988; McClintock and Janssen, 1990; Wahl and Hay, 1995), while having no demonstrable role in others (Kerr and Paul, 1995).

Most of the associational escapes discussed above are opportunistic rather than coevolved and, as such, may be used by many organisms in a wide variety of situations (Hay, 1986). There are, however, more intimate chemically-mediated associations that may be coevolved. Many marine microbes are predictably associated with specific species of marine macro-organisms. Because of the broad ability of marine microbes to produce bioactive secondary metabolites (Fenical, 1993), many host organisms could be coevolved with certain microbes because the microbes produce compounds that defend 
the host from natural enemies. As an example, embryos of the shrimp Palaemon macrodactylus are consistently covered by a strain of the bacterium Alteromonas sp. Removal of the bacterium results in $>90 \%$ mortality of the embryos because the bacterium produces 2,3-indolinedione, which chemically defends the embryos against attack by a pathogenic fungus (Gil-Turnes et al., 1989). It is possible that many of the ecologically important compounds found in benthic invertebrates could actually be produced by symbiotic microbes. A recent investigation of the symbiotic cyanobacteria from the sponge Dysidea herbacea (Unson and Faulkner, 1994) demonstrated that the sponge metabolites were located exclusively within the microbial symbionts rather than the sponge itself. These findings suggest that symbiotic microbes might commonly produce compounds that defend their hosts.

As a final example (Thuesen, 1991), predatory chaetognaths in planktonic systems subdue their copepod prey using a venom that contains the neurotoxin TTX (= tetrodotoxin). TTX appears to be produced by symbiotic bacteria living in the heads of the chaetognaths. The venom of a tropical octopus and the deterrent skin secretions of several marine fishes and terrestrial amphibians also contain TTX, which appears to be produced by similar bacterial symbionts. Thuesen (1991) hypothesizes that the TTX in chaetognaths also functions as a chemical defense against predation - as appears to be the case for some pufferfishes. It is interesting that chaetognaths selectively release copepods that are infested with bacteria. Chaetognaths might release infested copepods because bacteria from the copepods could compete with the chaetognath's TTX producing bacteria and reduce venom production or defense. The bacteria infesting the copepods are thus providing an associational escape for the copepod, just as bacteria in the chaetognath may be providing its host with protection.

In general, the biodiversity and ecological importance (both chemically-mediated and otherwise) of marine microbes appears grossly understudied and underappreciated. If molecular biology, improved culture techniques, and investigations of microbial systematics combine to make ecologically realistic investigations of marine microbes more tractable, then future investigations in marine microbial ecology will undoubtedly be tremendously productive.

Curiously, almost all studies on associational resistance only consider the benefits to a palatable species of experiencing reduced losses to consumers when associated with other species. As protection in these cases is rarely complete, it is reasonable to expect that the less palatable partner in such an association may encounter an increase in predation caused by the presence of the attractive species. This reversal of associational resistance has been called "shared doom" and has been demonstrated to occur when palatable epiphytic seaweeds foul less palatable host seaweeds that then become more susceptible to sea urchin grazing (Wahl and Hay, 1995). The urchins appear to detect fouled seaweeds from a distance as having an attractiveness that is an average of the host's and the epiphyte's separate palatabilities. The chemical mechanisms involved in this are unknown.

\section{Ontogeny of defense}

Few studies have addressed changes in chemical defenses as a function of age or 
developmental stage, but such changes clearly occur. Paul and Van Alstyne (1988) found that juvenile Halimeda plants were less calcified but more chemically noxious than adult plants and Lindquist and Hay (1996) found that chemical defenses of some benthic invertebrates were more highly developed in the larvae than in the adults.

More extensive studies are needed to determine how chemical defenses vary through ontogeny. Initial terrestrial studies on this topic asked, "why are embryos so tasty?" and hypothesized that potent chemical defenses and rapidly developing juvenile tissues were fundamentally incompatible because the toxic compounds would interfere with normal development. This is clearly not an absolute constraint for marine organisms, several of which produce larvae containing potent chemical defenses against predators (Lindquist et al., 1992; Lindquist and Hay, 1996; and references therein). As an example, Lindquist and Hay (1996) investigated larvae from 30 species of invertebrates for palatability and, for some species, chemical defenses. They found that brooded larvae of Caribbean sponges and gorgonians, and of hydroids and a bryozoan from temperate North Carolina, were all unpalatable to co-occurring fishes. In contrast, brooded larvae of temperate ascidians, a temperate sponge, and of Caribbean hard corals were readily consumed by fishes, as were larvae from 4 of 6 species of synchronous broadcast spawning gorgonians from the Caribbean. Survivorship and metamorphosis of attacked hut rejected larvae were indistinguishable from survivorship and metamorphosis of unattacked control larvae, indicating that fishes rejected unpalatable larvae without damaging them significantly. When the ability of 5 larval vs. adult extracts to deter fish feeding was tested, all 5 larval extracts were deterrent, while only 3 of 5 adult extracts deterred fish feeding. Among chemically rich taxa, brooded larvae were significantly more likely to be unpalatable than larvae of broadcast spawners. In general, distasteful larvae tended to be large, brightly colored, and released during the day, while palatable larvae tended to be less colorful and released at night. Studies are now needed to assess changes in defenses, if any, that coincide with settlement, metamorphosis, and progression to the adult stages. If toxic metabolites are incompatible with rapid developmental shifts, then defended larvae might lower their chemical defenses at the time of metamorphosis. Marine invertebrates offer an excellent system for assessing this hypothesis.

\section{Physiological effects of defensive compounds on natural enemies}

Many studies demonstrate that specific secondary metabolites deter consumer feeding. The advantages of these compounds for the prey are obvious. The reasons that consumers recognize and avoid particular compounds are less well understood because there have been few ecologically realistic investigations of the effects of marine secondary metabolites on consumer physiology rather than consumer feeding behavior. For the huge majority of metabolites that deter consumers, we don't know if they affect survivorship, growth, or fecundity, or if they just taste bad and are avoided even though they might have no negative effects on consumer fitness.

Consumers that are not food limited would be under minimal selection to recognize and consume all useful prey. This could result in prey commonly containing compounds that affect consumer behavior without having negative effects on consumer fitness. In 
contrast, consumers experiencing food limitation should be selected to avoid foods that lower their fitness but to consume foods that do not, regardless of their taste. However, even under these conditions, prey might chemically mimic more potent metabolites by making non-toxic compounds with structural groups that bind to prey receptors for toxic compounds. Until we know much more about the neurophysiology of consumers, some of these potential mechanisms of deterrence may be impossible to evaluate.

Direct tests of the effects of defensive metabolites on consumer physiology or fitness are rare, in part because it is very difficult to get consumers to eat defended prey so that the effects of the compounds can be assessed. Hay et al. (1987) demonstrated that a diterpene alcohol that deters fish from consuming the brown alga Dictyota significantly slowed fish growth rate when the compound was consumed as $1 \%$ of the diet for a period of several days. The ecological relevance of this assay can be questioned because although this concentration can occur in some tropical species of the Dictyotales, it is extremely unlikely that any fish would consume nothing but one of these species for an extended period. A different approach was taken by Targett and Targett (1990) who assayed the effect of crude extracts from a deterrent green seaweed by coating this on a palatable seagrass and evaluating its effects on parrotfish assimilation efficiency. Although the extract had no effect on assimilation efficiency, this does not exclude the possibility of negative effects on growth, development, or fecundity. Irelan and Horn (1991) tested the physiological effects of Fucus extract (which the fish would not eat), by anesthetizing fish and force feeding them control diets versus diets treated with the Fucus extracts, and then determining their digestive efficiency over the next several days. These treatments did not affect digestion of carbon, but Fucus polar extract did lower $\mathrm{N}$ assimilation efficiency relative to the control. Boettcher and Targett (1993) used a similar approach to test the effects of different sized algal phlorotannins on fish digestive efficiency and found that larger phlorotannins commonly suppressed digestive efficiency, while smaller ones did not. Their findings clearly show the limitations of measuring total phenolics (what most biologists do) and treating these values as if all phlorotannins have equivalent functions.

Lindquist and Hay (1995) found that consuming even very limited amounts of a chemically defended prey could negatively affect consumer fitness. They fed anemones large meals of nutritious food followed several hours later by small meals of larval mimics containing either defensive compounds (treatment) or no defensive compounds (controls). This was meant to mimic anemones getting the majority of their food from appropriate sources, but feeding at low levels ( $1.8 \%$ of the total daily diet) on defended foods (e.g., consuming a few chemically-rich invertebrate larvae). Even this low level of feeding on defended prey could have selected for avoidance of foods containing these defenses because both growth and vegetative reproduction of the treatment anemones declined dramatically.

Ecologically realistic assays involving long-term consumption of diets or secondary metabolites that do and do not deter feeding by consumers would be especially useful in evaluating the relationship between (1) the effects of a compound on consumer behavior versus fitness, (2) the possibility of consumers inducing resistance to the effects of common defensive metabolites (Brattsten, 1992), and (3) the genetic versus phenotypic component of consumer susceptibility to the effects of these compounds. Obtaining 
adequate data for long lived consumers like fishes and urchins will be difficult, but more rapidly maturing animals like amphipods can produce data on growth, survivorship, and fecundity in as little at 3-4 weeks (Duffy and Hay, 1991a Cruz-Rivera and Hay, unpublished data 1996).

\section{New compounds from biological insights}

Initial advances in marine chemical ecology were based on ecological tests of natural products that chemists had already discovered, purified, and described (i.e., ecologists 'mined' compounds from the freezers of collaborating chemists). Chemists usually noted these compounds because they produced "unusual" chromatographic patterns, not necessarily because they possessed interesting ecological functions. This approach could miss ecologically important compounds that are present in only trace amounts, those that have unusual biological activities rather than chromatographic characteristics, those that are water soluble and not amenable to several of the commonly used chromatographic methodologies, or those that degrade rapidly during storage, extraction, or separation and purification.

Marine chemical ecologists now commonly use bioassay guided fractionation schemes to detect, separate, and purify ecologically important metabolites (Cronin et al., 1995 is one recent example). This will lead to the detection of new compounds, and perhaps new groups of compounds, with potent biological activities. Recent examples of this include: (1) pigments from Antarctic sponges functioning as feeding deterrents against sea stars (J. McClintock and B. Baker, pers. comm.), (2) volatile algal hydrocarbons that attract sperm to brown algal eggs also serving as strong feeding deterrents against herbivorous amphipods (Hay and Boland, unpublished data 1996), and (3) an undescribed feeding deterrent from the red alga Calanotiphyllum medium, an undescribed butanol-soluble deterrent from Sargassum filipendula, and both butanol and water-soluble deterrents from the brown alga Fucus vesiculosus (M. Deal, M.E. Hay, and E. Cole, work in progress). Because polar metabolites can rapidly leach into the water, conducting ecologically realistic assays with polar metabolites can be difficult. Methodological improvements in this area (perhaps microencapsulation) would be especially welcome.

\section{Applied aspects}

In addition to the ecological aspects discussed above, marine chemical ecology produces discoveries with significant applied potential. Although terrestrial biodiversity has formed the foundation of the modern pharmaceutical industry; it has only been within the past decade that the enormous biodiversity in the world's oceans has been recognized and world-wide programs established to evaluate the biomedical utility of marine secondary metabolites (Jones, 1994). Marine metabolites are being tested or have been developed as antibiotics, pain suppressers, anti-inflammatory agents, molecular probes, skin care products, sun screens, and anticancer agents (Fautin, 1988; Attaway and Zaborsky, 1993). Some unique compounds that proved to be unsuitable as drugs 
have been useful as molecular probes yielding new insights into human disease. The classical use of tetrodotoxin and saxitoxin as probes of ion channel nerve transmission (Takahashi, 1979) helped form a foundation for more recent biomedical uses of other marine secondary metabolites.

Although most of the marine secondary metabolites that are presently being explored or developed for commercialization are from macro-organisms, the world's oceans contain a massive number of marine microbes, with most species probably being unknown. One such microorganism, the dinoflagellate Prorocentrum lima, was found to produce okadaic acid, a unique member of a new class of polyethers. Although first recognized as a causative agent in Diahrretic Shellfish Poisoning (DSP), the compound was later found to possess unprecedented inhibitory properties against phosphatase enzymes, thus leading to its current utilization as an important tool in the study of cell-cycle protein phosphorylation.

Although biomedical applications are being actively pursued, other potential applications of marine chemical ecology remain unrecognized or poorly developed. As a few possible examples: (1) Numerous natural antifouling substances are not being aggressively pursued because presently used products are working well and are legal - despite the toxic nature and potential for environmental harm represented by some of the products being used; (2) Some marine metabolites being tested as anticancer drugs occur at low concentrations and only in a few populations of the producer organisms (see the above discussion of bryostatin 1). This makes the drugs difficult to harvest in quantities adequate for testing. Understanding physical and biological regimes influencing metabolite production (Cronin and Hay, 1996b,c) might allow metabolite concentrations to be enhanced enough to provide the drugs via aquaculture efforts; and (3) Crab predation on seed clams used to establish commercial clam cultures in natural settings can cause up to $90 \%$ loss of outplanted juveniles (D. Brady, personal communication). Recently acquired insights into the chemical cues that crabs use while foraging on bivalves and how these cues are affected by flow regimes and substrate morphology (Weissburg and ZimmerFaust, 1993; Zimmer-Faust et al., 1995) might allow losses to be reduced considerably with minimal additional cost. Clearly, marine chemical ecology can contribute substantially to both the applied and basic sciences. Each aspect deserves further development.

\section{Conclusions}

Thousands of marine secondary metabolites have been identified. Many have been demonstrated to deter consumers; a few appear to suppress competitors, pathogens, or fouling organisms. The greater evidence for secondary metabolites serving as chemical defenses against consumers may be related to the strong selection that consumers impose on prey or may simply be a function of the greater ease of conducting ecologically realistic experiments with consumers. More novel, rigorous, and ecologically relevant methodologies need to be developed and applied to investigations of allelopathy, antifouling, antimicrobial, and other possible functions of secondary metabolites.

There are numerous investigations of how marine secondary metabolites affect consumer feeding behavior, but few of how these metabolites affect consumer fitness 
when eaten. Studies are needed to determine how consumers perceive secondary metabolites (i.e., neurophysiology) and how ecologically realistic doses of these metabolites affect growth, reproduction, and survivorship of consumers.

Studies assessing spatial and temporal patterns of chemical defenses are limited but suggest that defenses are better developed in tropical than temperate communities, in local habitats with many consumers than in nearby habitats with few consumers, and that intraspecific variance in chemical defenses can be large and affected by induction due to previous attack or by physical stresses such as desiccation and exposure to near-surface levels of UV radiation. Intraspecific variance in chemical defense and susceptibility to consumers can be dramatic. Investigations are needed to determine: (i) which consumers and types of damage result in alterations of prey chemical defenses, (ii) how these responses vary in environments with differing physical characteristics, (iii) whether the 'induced' responses are a direct response to consumer attack or are a defense against microbial pathogens that may be entering through feeding wounds, and (iv) the potential effects of these induced defenses on consumer fitness.

Defensive metabolites have important ecological consequences, but they do not act in isolation from other characteristics of the organism or from the physical and biological environment in which organisms interact with their natural enemies. Marine chemical ecology needs to be integrated into a broader and more complex framework that includes aspects of physiological, population, community, and even ecosystem ecology. Even simple aspects of chemical defenses will not be adequately understood unless they are integrated with additional types of prey defenses and viewed within the context of the nutritional value and physiological state of the organisms they are protecting.

Although relatively unstudied, ontogenetic shifts in concentrations and types of defenses occur in seaweeds, benthic invertebrates, and phytoplankton. Investigations assessing the ecological consequences of these shifts should be especially productive. Initial hypotheses regarding the effects of larval chemical defenses on the evolution of complex life cycles and differing modes of development among marine invertebrates (Lindquist and Hay, 1996) are in need of extension and broader testing.

Marine microbes produce a wide variety of strongly bioactive secondary metabolites that can have devastating indirect, and ecosystem-wide, effects on non-target organisms (e.g., red tide related fish kills). The natural function of these metabolites are poorly understood, but the few ecologically realistic studies that have been conducted indicate that the compounds may serve to deter both consumers and other microbes. Additionally, macro-organisms may commonly use metabolites produced by their microbial symbionts to deter consumers, subdue prey, and defend their embryos from microbial pathogens. The study of microbial chemical ecology offers unlimited possibilities for innovative investigators that develop rigorous and more ecologically relevant experimental approaches.

\section{Acknowledgments}

My work on chemical ecology has profited greatly from funding provided by the U.S. National Science Foundation and from the chemical insight, help, training, and 
occasional badgering provided by William Fenical, Niels Lindquist, and Valerie Paul. Aid for preparation of this paper came from NSF grants OCE 92-02847 and 95-29784. Input from J. Estes, W. Fenical, N. Lindquist, J. McClintock, R.M. Newman, V.J. Paul, J. Pawlik, P.D. Steinberg, R. Steneck, N.M. Targett, M. Wahl, R. Zimmer-Faust, and two anonymous reviewers improved the manuscripl.

\section{References}

Alder, R.A. and R. Karban, 1994. Defended fortresses or moving targets? Another model of inducible defenses inspired by military metaphors. Am. Nat., Vol. 144, pp. 813-832.

Alstad, D.N. and D.A. Andow, 1995. Managing the evolution of insect resistance to transgenic plants. Science, Vol. 268, pp. 1894-1896.

Atsatt, P.R. and D.J. O'Dowd, 1976. Plant defense guilds. Science, Vol. 193, pp. 24-29.

Attaway, D.H. and O.R. Zaborsky, 1993. Marine biotechnology volume I, pharmaceutical and bioactive natural products. Plenum Press, New York.

Bakus, G.J. and G. Green, 1974. Toxicity in sponges and holothurians: a geographic pattern. Science, Vol. 185 , pp. 951-953.

Bakus, G.J., N.M. Targett and B. Schulte, 1986. Chemical ecology of marine organisms: an overview. $J$. Chem. Ecol., Vol. 12, pp. $951-987$.

Baldwin, I.T., 1990. Herbivory simulation in ecological research. TREE, Vol. 5, pp. 91-93.

Baldwin, I.T., 1994. Chemical changes rapidly induced by folivory. In, Insect-plant interactions, Vol. 5, edited by E.A. Bernays, CRC Press, Boca Raton. pp. 1-23.

Barkai, A. and C. McQuaid, 1988. Predator-prey role reversal in a benthic marine ecosystem. Science, Vol. 242, pp. 62-64.

Bell, S.S., 1991. Amphipods as insect equivalents? an alternative view. Ecology, Vol. 72, pp. 350-354.

Bertness, M.D., S.D. Garrity and S.C. Levings, 1981. Predation pressure and gastropod foraging: a tropicaltemperate comparison. Evolution, Vol. 35, pp. 995-1007.

Boettcher, A.A. and N.M. Targett. 1993. Role of polyphenolic molecular size in reduction of assimilation efficiency in Xiphister mucosus. Ecology, Vol. 74, pp. 891-903.

Bolser, R.C. and M.E. Hay, 1996. Are tropical plants better defended? Palatability and defenses of temperate versus tropical seaweeds. Ecology, Vol. 77, in press.

Brattsten, L.B., 1992. Metabolic defenses against plant allelochemicals. In, Herbivores: their interaction with secondary metabolites, evolutionary and ecological processes, edited by G.A. Rosenthal and M.R. Berenbaum, Academic Press, San Diego, pp. 176-242.

Brawley, S.H., 1992. Mesoherbivores. In, Plant-animal interactions in the marine benthos, edited by D.M. John, S.S. Hawkins and J.H. Price, Systematics Association Special Volume, Clarendon Press, Oxford, pp. $235-264$.

Bryan, P.J., W.Y. Yoshida, J.B. McClintock and B.J. Baker, 1995. Ecological role for pteroenone, a novel antifeedant from the conspicuous antarctic pteropod Clione antarctica (Gymnosomata: Gastropoda). Mar. Biol., Vol. 122, pp. 271-277.

Carpenter, R.C., 1986. Partitioning herbivory and its effects on coral reef algal communities. Ecol. Monogr., Vol. 56, pp. 345-365.

Chanas, B. and J.R. Pawlik, 1995. Defense of Caribbean sponges against predatory reef fish. Il. spicules, tissue toughness, and nutritional quality. Mar. Ecol. Prog. Ser., Vol. 127, pp. 195-211

Coley, P.D. and T.M. Aide, 1990. Comparison of herbivory and plant defenses in temperate and tropical broad-leaved forests. In, Plant-animal interactions: evolutionary ecology in tropical and temperate regions, edited by P.W. Price, T.M. Lewinsotin, G.W. Fernandes and W.W. Benson, Wiley, New York, pp. 25-49.

Cronin, G. and M.E. Hay, 1996a. Within-plant variance in seaweed chemical defenses: Optimal defense theory versus the growth-differentiation balance hypothesis. Oecologia, Vol.105, pp. 361-368.

Cronin, G. and M.E. Hay, 1996b. Susceptibility to herbivores depends on recent history of both the plant and animal. Ecology, Vol. 77, pp. 1531-1543. 
Cronin, G. and M.E. Hay, 1996c. Amphipod grazing and induction of seaweed chemical defenses. Ecology, Vol. 77, in press.

Cronin, G. and M.E. Hay, 1996d. Effects of light and nutrient availability on the growth, secondary chemistry, and resistance to herbivory of two brown seaweeds. Oikos, Vol. 77, in press.

Cronin, G., M.E. Hay, W. Fenical and N. Lindquist, 1995. Distribution, density, and sequestration of host chemical defenses by the specialist nudibranch Tritonia hamnerorum found at high densities on the sea fan Gorgonia ventalina. Mar. Ecol. Prog. Ser., Vol. 119, pp. 177-189.

Denno, R.F. and M.S. McClure, 1983. Variable plants and herbivores in natural and managed systems. $\Lambda$ cademic Press, New York. 717 pp.

de Nys, R., J.C. Coll and I.R. Price, 1991. Chemically mediated interactions between the red alga Plocamium hamatum (Rodophyta) and the octocoral Sinularia cruciata (Alcyonacea). Mar. Biol., Vol. 108, pp. $315-320$.

de Nys, R., P.D.Steinberg, P. Willemsen, S.A. Dworjanyn, C.L. Gabelish and R.J.King, 1995. Broad spectrum effects of secondary metabolites from the red alga Delisea pulchra in antifouling assays. Biofouling, Vol. 8 , pp. 259-271.

Duffy, J.E. and M.E. Hay, 1990. Seaweed adaptations to herbivory. Bioscience, Vol. 40, pp. 368-375.

Duffy, J.E. and M.E. Hay, 1991a. Food and shelter as determinants of food choice in an herbivorous marine amphipod. Ecology, Vol. 72, pp. 1286-1298.

Duffy, J.E. and M.E. Hay, 199lb. Not all amphipods are created equal: a reply to Bell. Ecology, Vol. 72, pp. 354-358.

Duffy, J.E. and M.E. Hay, 1994. Herbivore resistance to seaweed chemical defense: the roles of mobility and predation risk. Ecology, Vol. 75, pp. 1304-1319.

Duffy, J.E. and V.J. Paul, 1992. Prey nutritional quality and the effectiveness of chemical defenses against tropical reef fishes. Oecologia, Vol. 90, pp. 333-339.

Duggins, D.O., C.A. Simenstad and J.A. Estes, 1989. Magnification of secondary production by kelp detritus in coastal marine ecosystems. Science, Vol. 245, pp. 170-173.

Estes, J.A. and P.D. Steinberg, 1988. Predation, herbivory, and kelp evolution. Paleobiology, Vol. 14, pp. $19-36$.

Faulkner, D.J., 1994. Marine natural products. Nat. Prod. Rep., Vol. 11, pp. 355-394.

Fautin, D.G., 1988. The biomedical importance of marine organisms. Memoirs of the California Academy of Sciences \#13, California Academy of Sciences, San Francisco.

Feeny, P., 1970. Seasonal changes in oak leaf tannins and nutrients as a cause of spring feeding by winter moth caterpillars. Ecology, Vol. 51, pp. 565-581.

Feifarek, B.P., 1987. Spines and epibionts as antipredator defenses in the thorny oyster Spondylus americanus Hermann. J. Exp. Mar. Biol. Ecol., Vol. 105, pp. 39-56.

Fenical, W., 1993. Chemical studies of marine bacteria: developing a new resource. Chem. Rev., Vol. 93, pp. $1673-1683$.

Fritz, K.S. and E.L. Simms, 1992. Plant resistance to herbivores and pathogens. University of Chicago Press, Chicago. $590 \mathrm{pp}$.

Gerhart, D.J., D. Rittschof and S.W. Mayo, 1988. Chemical ecology and the search for marine antifoulants. $J$. Chern. Ecol., Vol. 14, pp. 1905-1917.

Gil-Turnes, M.S., M.E. Hay and W. Fenical, 1989. Symbiotic marine bacteriachemically defend crustacean embryos from a pathogenic fungus. Science, Vol. 246, pp. 116-118.

Harvell, C.D. 1990. The ecology an evolution of inducible defenses. Quar. Rev. Biol., Vol. 65. pp. 323-341.

Harvell, C.D. and W. Fenical, 1989. Chemical and structural defenses of Caribbean gorgonians (Pseudopterogorgia spp.): intracolony localization of defense. Limnol. Oceanogr., Vol. 34, pp. 382-389.

Harvell, C.D., W. Fenical and C.H. Green, 1988. Chemical and structural defenses of Caribbean gorgonians (Pseudopterogorgia spp.). I. development of an in situ feeding assay. Mar. Ecol. Prog. Ser., Vol. 49, pp. 287-294.

Harvell, C.D., W. Fenical, V. Roussis, J.L. Ruesink, C.C. Griggs and C.H. Greene, 1993. Local and geographic variation in the defensive chemistry of a West Indian gorgonian coral (Briareum asbestinum). Mar. Ecol. Prog. Ser., Vol. 93, pp. 165-173.

Hay, M.E., 1984. Predictable spatial escapes from herbivory: how do these affect the evolution of herbivore resistance in tropical marine communities? Oecologia, Vol. 64, pp. 396-407. 
Hay, M.E., 1985. Spatial patterns of herbivore impact and their importance in maintaining algal species richness. Proc. 5th Int. Coral Reef Congr., Vol.4, pp. 29-34.

Hay, M.E., 1986. Associational plant defenses and the maintenance of species diversity: turning competitors into accomplices. Am. Nat., Vol. 128, pp. 617-641.

Hay, M.E., 1991a. Fish-seaweed interactions on coral reefs: effects of herbivorous fishes and adaptations of their prey. In, The ecology of coral reef fishes, edited by P.F. Sale, Academic Press, New York, pp. 96-119.

Hay, M.E., 1991b. Marine-terrestrial contrasts in the ecology of plant chemical defenses against herbivores. TREE, Vol. 6, pp. 362-365.

Hay, M.E. 1992, Seaweed chemical defenses: their role in the cvolution of fccding spccialization and in mediating complex interactions. In, Ecological roles for marine secondary metabolites; explorations in chemical ecology series, edited by V.J. Paul, Comstock Publishing Associates, Ithaca, pp. 93-118.

Hay, M.E. and W. Fenical, 1988. Marine plant-herbivore interactions: the ecology of chemical defense. Annu. Rev. Ecol. Syst., Vol. 19, pp. 111-145.

Hay, M.E. and W. Fenical, 1992. Chemical mediation of seaweed-herbivore interactions. In, Plant-animal interactions in the marine benthos, edited by D.M. John, S.S. Hawkins and J.H. Price, Systematics Association Special Volume, Clarendon Press, Oxford, pp. 319-337.

Hay, M.E. and W. Fenical, 1996. Chemical ecology and marine biodiversity: insights and products from the sea. Oceanography, Vol. 9, pp. 10-20.

Hay, M.E. and P.D. Steinberg, 1992. The chemical ecology of plant-herbivore interactions in marine versus terrestrial communities. In, Herbivores: their interaction with secondary metabolites, evolutionary and ecological processes, edited by J.A. Rosenthal and M.R. Berenbaum, Academic Press, San Diego. pp. $371-413$.

Hay, M.E., J.E. Duffy, C.A. Pfister and W. Fenical, 1987. Chemical defenses against different marine herbivores: are amphipods insect equivalents? Ecology, Vol. 68, pp. 1567-1580.

Ilay, M.E., V.J. Paul, S.M. Lewis, K. Gustafson, J. Tucker and R.N. Trindell, 1988. Can tropical seaweeds reduce herbivory by growing at night? diel patterns of growth, nitrogen content, herbivory, and chemical versus morphological defenses. Oecologia, Vol. 75, pp. 233-245.

Hay, M.E., J.E. Duffy and W. Fenical, 1990. Host-plant specialization decreases predation on a marine amphipod: an herbivore in plant's clothing. Ecology, Vol. 71, pp. 733-743.

Hay, M.E., Q.E. Kappel and W. Fenical, 1994. Synergisms in plant defenses against herbivores: interactions of chemistry, calcification, and plant quality. Ecology. Vol. 75, pp. 1714-1726.

Heck, K.L. Jr. and K.A. Wilson, 1987. Predation rates on decapod crustaceans in latitudinally separated seagrass communities: a study of spatial and temporal variation using tethering techniques. J. Exp. Mar. Biol. Ecol., Vol. 107, pp. 87-100.

Herms, D.A. and W.J. Mattson, 1992. The dilemma of plants: to grow or to defend? Quart. Rev. Biol., Vol. 67 , pp. 283-335.

Horn, M.H., 1989. Biology of marine herbivorous fishes. Oceanogr. Mar. Biol. Annu Rev., Vol. 27, pp. $167-272$.

Huntley, M., P. Sykes, S. Rohan and V. Martin, 1986. Chemically-mediated rejection of dinoflagellate prey by the copepods Calanus pacificus and Paracalanus parvus: mechanism, occurrence and significance. Mar. Ecol. Prog. Ser., Vol. 28, pp. 105-120.

Irelan, C.D. and M.H. Horn, 1991. Effects of macrophyte secondary chemicals on food choice and digestive efficiency of Cebidichthys violaceus (Girard), an herbivorous fish of temperate marine waters. J. Exp. Mar. Biol. Ecol., Vol. 153, pp. 179-194.

Jackson, J.B.C., 1977. Competition on marine hard substrata: the adaptive significance of solitary and colonial stategies. Am. Nat., Vol. 111, pp. 743-767.

Jones, A.. 1994. The pharma-sea. Financial World, Vol. 163, pp. 24-29.

Karban, R., 1992. Plant variation: its effects on populations of herbivorous insects. In, Plant resistance to herbivores and pathoghens. edited by R.S. Fritz and E.L. Simms, Univ. of Chicago Press, Chicago, pp. $195-215$.

Kerr, J.N.Q. and V.J. Paul, 1995. Animal-plant defense association: the soft coral Sinularia sp. (Cnidaria, Alcyonacea) protects Halimeda species from herbivory. J. Exp. Mar. Biol. Ecol., Vol. 186, pp. 183-205.

King, G.M., 1986. Inhibition of microbial activity in marine sediments by a bromophenol from a hemichordate. Nature, Vol. 323, pp. 257-259. 
Kvitek, R.G., A.R. DeGange and M.K. Beitler, 1991. Paralytic shellfish poisoning toxins mediate feeding behavior of sea otters. Limnol. Oceanogr., Vol. 36, pp. 393-404.

Lessios, H.A., 1988. Mass mortality of Diadema antillarum in the Caribbean: what have we learned? Annu. Rev. Ecol. Syst., Vol. 19, pp. 371-393.

Lindquist, N. and M.E. Hay, 1995. Can small rare prey be chemically defended? the case for marine larvae. Ecology, Vol. 76, pp. 1347-1358.

Lindquist, N. and M.E. Hay, 1996. Palatability and chemical defense of marine invertebrate larvae. Ecol. Monogr. Vol. 66, pp. 431-450.

Lindquist, N.L., M.E. Hay and W. Fenical, 1992. Chemical defense of ascidians and their conspicuous larvae. Ecol. Monogr., Vol. 62, pp. 547-568.

Littler, M.M. and D.S. Littler, 1995. Impact of CLOD pathogen on Pacific coral reefs. Science, Vol. 267, pp. $1356-1360$.

Littler, M.M., P.R. Taylor and D.S. Littler, 1986. Plant defense associations in the marine environment. Coral Reefs, Vol. 5, pp. 63-71.

Lubchenco, J. and S.D. Gaines, 1981. A unified approach to marine plant-herbivore interactions. I. populations and communities. Annu. Rev. Ecol. Syst., Vol. 12, pp. 405-437.

Lumbang, W.A. and V.J. Paul, 1996. Chemical defense of the tropical green seaweed Neomeris annulata Dickie: effects of multiple compounds on feeding by herbivores. J. Exp. Mar. Biol. Ecol. in press.

McClintock, J. B, 1994. An overview of the chemical ecology of Antarctic marine invertebrates, the Ireland lecture 1993. The University of Alabama at Birmingham, $24 \mathrm{pp}$.

McClintock, J.B. and J. Janssen, 1990. Pteropod abduction as a chemical defense in a pelagic antarctic amphipod. Nature, Vol. 346, pp. 462-464.

Menge, B.A. and J. Lubchenco, 1981. Community organization in temperate and tropical rocky intertidal habitats: prey refuges in relation to consumer pressure gradients. Ecol. Monogr., Vol. 51, pp. 429-450.

Meyer, K.D. and V.J. Paul, 1992. Intraplant variation in secondary metabolite concentration in three species of Caulerpa (Chlorophyta: Caulerpales) and its effects on herbivorous fishes. Mar. Ecol. Prog. Ser., Vol. 82, pp. 249-257.

Meyer, K.D. and V.J. Paul, 1995. Variation in secondary metabolite and aragonite concentrations in the tropical green seaweed Neomeris annulata: effects on herbivory by fishes. Mar. Biol., Vol. 122, pp. 537-545.

Paerl, H.W., 1988. Nuisance phytoplankton blooms in coastal, estuarine, and inland waters. Limnol. Oceanogr., Vol. 33, pp. 823-847.

Paul, VJ., 1992. Ecological roles of marine natural products. Comstock, Ithaca, 245 pp.

Paul, V.J. and W. Fenical, 1986. Chemical defense in tropical green algae, order Caulerpales. Mar. Ecol. Prog. Ser., Vol. 34, pp. 255-264.

Paul, V.J. and M.E. Hay, 1986. Seaweed susceptibility to herbivory: chemical and morphological correlates. Mar. Ecol. Prog. Ser., Vol. 33, pp. 255-264.

Paul, V.J. and K.L. Van Alstyne, 1988. Chemical defense and chemical variation in some tropical Pacific species of Halimeda (Halimedaceae; Chlorophyta). Coral Reefs, Vol. 6, pp. 263-270.

Paul, V.J. and K.L. Van Alstyne, 1992. Activation of chemical defenses in the tropical green algae Halimeda spp. J. Exp. Mar. Biol. Ecol., Vol. 160, pp. 191-203.

Pawlik, J.R., 1992. Chemical ecology of the settlement of benthic marine invertebrates. Oceanogr. Mar. Biol. Annu. Rev., Vol. 30, pp. 273-335.

Pawlik, J.R., 1993. Marine invertebrate chemical defenses. Chem. Rev., Vol. 93, pp. 1911-1922.

Pawlik, J.R., M.T. Burch and W. Fenical, 1987. Patterns of chemical defenses among Caribbean gorgonian corals: a preliminary survey. J. Exp. Mar. Biol. Ecol., Vol. 108, pp. 55-66.

Pawlik, J.R., B. Chanas, R.J. Toonen and W. Fenical, 1995. Defenses of Caribbean sponges against predatory reef fish. I. chemical deterrency. Mar. Ecol. Prog. Ser., Vol. 127, pp. 183-194.

Pennings, S.C. and V.J. Paul, 1992. Effect of plant toughness, calcification, and chemistry on herbivory by Dolabella auricularia. Ecology, Vol. 3, pp. 1606-1619.

Pennings, S.C., M.P. Puglisi, T.J. Pitlik, A.C. Himaya and V.J. Paul, 1996. Effects of secondary metabolites and $\mathrm{CaCO}_{3}$ on feeding by surgeonfishes and parrotfishes: within-plant comparisons. Mar. Ecol. Prog. Ser., in press.

Pettit, G.R., 1991. The bryostatins. Prog. Chem. Org. Nat. Prod., Vol. 57, pp. 153-195. 
Pfister, C.A., 1992. Costs of reproduction in an intertidal kelp: patterns of allocation and life history consequences. Ecology, Vol. 73, pp. 1586-1596.

Pfister, C.A. and M.E. Hay, 1988. Associational plant refuges: convergent pattems in marine and terrestrial communities result from differing mechanisms. Oecologia, Vol. 77, pp. 118-129.

Poore, A.G.B., 1994. Selective herbivory by amphipods inhabiting the brown alga Zonaria angustata. Mar. Ecol. Prog. Ser., Vol. 107, pp. 113-123.

Porter, J.W. and N.M. Targett, 1988. Allelochemical interactions between sponges and corals. Biol. Bull., Vol. 175 , pp. $230-239$.

Raffa, K.F. and E.B. Smalley, 1995. Interaction of pre-attack and induced monoterpene concentrations in host conifer defense against bark beetle-fungal complexes. Oecologia, Vol. 102, pp. 285-295.

Raghukumar, C. and D. Chandramohan, 1988. Changes in the marine green alga Chaetomorpha media on infection by a fungal pathogen. Bot. Mar., Vol. 31, pp. 311-315.

Renaud, P.E., M.E. Hay and T.M. Schmitt, 1990. Interactions of plant stress and herbivory: interspecific variation in the susceptibility of a palatable versus an unpalatable seaweed to sea urchin grazing. Oecologia, Vul. 82, pp. 217-226.

Sakata, K., 1989. Feeding attractants and stimulants for marine gastropods. In, Bioorganic Marine Chemistry, Volume 3, edited by P.J. Scheuer, Springer-Verlag, Berlin, pp. 115-129.

Sammarco, P.W. and J.C. Coll, 1992. Chemical adaptations in the Octocorallia: evolutionary considerations. Mar. Ecol. Prog. Ser., Vol. 88, pp. 93-104.

Schmitt, T.M., M.E. Hay and N. Lindquist, 1995. Constraints on chemically mediated coevolution: multiple functions of seaweed secondary metabolites. Ecology, Vol. 6, pp. 107-123.

Schultz, J.C., M.D. Hunter and H.M. Appel, 1992. Antimictobial activity of polyphenols mediates plantherbivore interactions. In, Plant phenols, edited by R.W. Hemmingway and P.E. Laks, Plenum Press, New York, pp. 621-637.

Schupp, P.J. and V.J. Paul, 1994. Calcification and secondary metabolites in tropical seaweeds: variable effects on herbivorous fishes. Ecology, Vol. 75, pp. 1172-1185.

Shaw, B.A., R.J. Anderson and P.J. Harrison, 1995a. Feeding deterrent properties of apo-fucoxanthinoids from marine diatoms. I. chemical structures of apo-fucoxanthinoids produced by Phaeodactylum tricornutum. Mar. Biol., Vol. 124, pp. 467-472.

Shaw, B.A., P.J. Harrison and R.J. Anderson, 1995b. Feeding deterrent properties of apo-fucoxanthinoids from marine diatoms. II. physiology of production fo apo-fucoxanthinoids by the marine diatoms Phaeodactylum tricornutum and Thalassiosira pseudonana, and their feeding deterrent effects on the copepod Tigriopus californicus. Mar. Biol., Vol. 124, pp. 473-481.

Simenstad, C.A., J.A. Estes and K.W. Kenyon, 1978. Aleuts, sea otters, and alternate stable-state communities. Science, Vol. 200, pp. 403-411.

Steinberg, P.D., 1984. Algal chemical defense against herbivores: allocation of phenolic compounds in the kelp Alaria marganitu. Science, Vol. 223, pp. 405-407.

Steinberg, P.D., 1989. Biogeographical variation in brown algal polyphenolics and other secondary metabolites: comparison between temperate Australasia and North America. Oecologia, Vol. 78, pp. 373-382.

Steinberg, P.D., 1992. Geographical variation in the interaction between marine herbivorcs and brown algal secondary metabolites. In, Ecological Roles for Marine Secondary Metabolites, edited by V.J. Paul, Comstock Publishing Associates, Ithaca, pp. 51-92.

Steinberg, P. D, 1994. I ack of short-term induction of phlorotannins in the Australasian brown algae Ecklonia radiata and Sargassum vestitum. Mar. Ecol. Prog. Ser., Vol. 112, pp. 129-133.

Steinberg, P.D., 1995. Interaction between the canopy dwelling echinoid Holopneustes purpurescens and its host kelp Ecklonia radiata. Mar. Ecol. Prog. Ser., Vol. 127, pp. 169-181.

Steinberg, P.D., J.A. Estes and F.C. Winter, 1995. Evolutionary consequences of food chain length in kelp forest communities. Proc. Nat. Acad. Sci. USA, Vol. 92, pp. 8145-8148.

Steinberg, P.D. and I.A. van Altena, 1992. Tolerance of marine invertebrate herbivores to brown algal phlorotannins in temperate Australasia. Ecol. Monogr., Vol. 62, pp. 189-222.

Takahashi, T., 1979. Modulation of nerve membrane sodium channels by neurotoxins. In, Advances in cytopharmacology, Vol. 3, edited by B. Ceccarelli and F. Clementi, Raven Press, New York, pp. $293-304$.

'lallamy, D.W. and M.J. Raupp, 1991. Phytochemical induction by herbivores. John Wiley, New York, 431 pp. 
Tamburri, M.N. and R.K. Zimmer-Faust, 1996. Suspension-feeding in oysters: basic mechanisms controlling recognization and ingestion of larvae. Limnol. Oceanogr., in press.

Targett, N.M., A.A. Boettcher, T.E. Targett and N.H. Vrolijk, 1995. Tropical marine herbivore assimilation of phenolic-rich plants. Oecologia, Vol, 103, pp. 170-179.

Targett, N.M., L.D. Coen, A.A. Boettcher and C.E. Tanner, 1992. Biogeographic comparisons of marine algal polyphenolics: evidence against a latitudinal trend. Oecologia, Vol. 89 , pp. 464-470.

Targett, T.E. and N.M. Targett, 1990. Energetics of food selection by the herbivorous parrotfish Sparisoma radians: roles of assimilation efficiency, gut evacuation rate, and algal secondary metabolites. Mar. Ecol. Prog. Ser., Vol. 66, pp. 13-21.

Thuesen, E.V., 1991. The tetrodotoxin venom of chaetognaths. In The biology of Chaetognaths, edited by Bone, Q., H. Kapp, and A.C. Pierrot-Bults, Oxford University Press, Oxford, pp. 55-60.

Tugwell, S. and G.M. Branch, 1989. Differential polyphenolic distibution among tissues in the kelps Ecklonia maxima, Laminaria pallida, and Macrocystis angustifolia in relation to plant defense theory. J. Exp. Mar. Biol. Ecol., Vol. 129, pp. 219-230.

Tuomi, J., H. Ilvessalo, P. Niemela, S. Siren and V. Jormalainen, 1989. Within-plant variation in phenolic content and toughness of the brown alga Fucus vesiculosus L. Bot. Mar., Vol. 32, pp. 505-509.

Unson, M. and D.J. Faulkner, 1994. Cyanobacterial symbiont biosynthesis of chlorinated metabolites from Dysidea herbaceae (Porifera). Experientia, Vol. 49, pp. 349-353.

Van Alstyne, K.L., 1988. Herbivore grazing increases polyphenolic defenses in the intertidal brown alga Fucus distichus. Ecology, Vol. 69, pp. 655-663.

Van Alstyne, K.L. and V.J. Paul, 1990. The biogeography of polyphenolic compounds in marine macroalgae: temperate brown algal defenses deter feeding by tropical herbivorous fishes. Oecologia, Vol. 84, pp. $158-163$.

Van Alstyne, K.L. and V.J. Paul, 1992. Chemical and structural defenses in the sea fan Gorgonia ventalina: effects against generalist and specialist predators. Coral Reefs, Vol. 11, pp. 155-159.

Van Alstyne, K.L., C.R. Wylie, V.J. Paul and K. Meyer, 1992. Antipredator defenses in tropical Pacific soft corals (Coelenterata: Alycyonacea). I. sclerites as defenses against generalist carnivorous fishes. Biol. Bull., Vol. 182, pp. 231-240.

van Donk, E. and D.O. Hessen, 1993. Grazing resistance in nutrient stressed phytoplankton. Oecologia, Vol. 93, pp. 508-511.

Vermeij, G.J., 1987. Evolution and escilation. Princeton University Press, Princeton, 527 pp.

Wahl, M. and M.E. Hay, 1995. Associational resistance and shared doom: effects of epibiosis on herbivory. Oecologia, Vol. 102, pp. 329-340.

Watterman, P.G. and S. Mole, 1994. Analysis of phenolic plant metabolites. Blackwell Scientific, Oxford. 238 pp.

Weissburg, M.J. and R.K. Zimmer-Faust, 1993. Life and death in moving fluids: hydrodynamic effects oon chemosensory-mediated predations. Ecology, Vol. 74, pp. 1428-1443.

Weissburg, M.J. and R.K. Zimmer-Faust, 1994. Odor plumes and how blue crabs use them in finding prey. $J$. Exp. Mar. Biol. Ecol., Vol. 197, pp. 349-375.

Woodin, S.A., R.L. Marinelli and D.E. Lincoln, 1993. Allelochemical inhibition of recruitment in a sedementary assemblage. J. Chem. Ecol., Vol. 19, pp. 517-530.

Yates, J.L. and P. Peckol, 1993. Effects of nutrient availability and herbivory on polyphenolics in the seaweed Fucus vesiculosus. Ecology, Vol. 74, pp. 1757-1766.

Zimmer-Faust, R.K., C.M. Finelli, N.D. Pentcheff and D.S. Wethey, 1995. Odor plumes and animal navigation in turbulent water flow: a field study. Biol. Bull., Vol. 188, pp. 111-116.

Zimmer-Faust, R.K., P.B. O'Neill and D.W. Schar, 1996a. The relationship between predator activity state and sensitivity to prey odors. Biol. Bull., Vol. 190: in press.

Zimmer-Faust, R.K., M.P. de Souza and D.C. Yoch, 1996b. Bacterial chemotaxis and its potential role in marine dimethylsulfide production and biogeochemical sulphur cycling. Limnol. Oceanogr., Vol. 41, in press. 